\title{
Enhancing crop resilience to combined abiotic and biotic stress through the dissection of physiological and molecular crosstalk
}

\section{Christos Kissoudis, Clemens van de Wiel, Richard G. F. Visser and Gerard van der Linden*}

Laboratory of Plant Breeding, Wageningen University, Wageningen, Netherlands

\section{Edited by:}

Thomas Debener, Leibniz Universität Hannover, Germany

\section{Reviewed by:}

Jan De Riek, Instituut voor Landbouwen Visserijonderzoek, Belgium Anna Maria Mastrangelo, CRA-Centro di Ricerca per la Cerealicoltura, Italy

\section{*Correspondence:}

Gerard van der Linden, Laboratory of Plant Breeding, Wageningen

University, Droevendaalsesteeg 1, 6708 PB Wageningen, Netherlands e-mail: gerard.vanderlinden@wur.nl
Plants growing in their natural habitats are often challenged simultaneously by multiple stress factors, both abiotic and biotic. Research has so far been limited to responses to individual stresses, and understanding of adaptation to combinatorial stress is limited, but indicative of non-additive interactions. Omics data analysis and functional characterization of individual genes has revealed a convergence of signaling pathways for abiotic and biotic stress adaptation. Taking into account that most data originate from imposition of individual stress factors, this review summarizes these findings in a physiological context, following the pathogenesis timeline and highlighting potential differential interactions occurring between abiotic and biotic stress signaling across the different cellular compartments and at the whole plant level. Potential effects of abiotic stress on resistance components such as extracellular receptor proteins, R-genes and systemic acquired resistance will be elaborated, as well as crosstalk at the levels of hormone, reactive oxygen species, and redox signaling. Breeding targets and strategies are proposed focusing on either manipulation and deployment of individual common regulators such as transcription factors or pyramiding of non- (negatively) interacting components such as R-genes with abiotic stress resistance genes. We propose that dissection of broad spectrum stress tolerance conferred by priming chemicals may provide an insight on stress cross regulation and additional candidate genes for improving crop performance under combined stress. Validation of the proposed strategies in lab and field experiments is a first step toward the goal of achieving tolerance to combinatorial stress in crops.

Keywords: salinity, drought, disease resistance, R-genes, crosstalk, hormones, transcription factors, posttranslational modifications

\section{INTRODUCTION}

Plants are sessile and cannot escape stressful conditions originating from the physical environment (abiotic stress) and from interactions with insects and microorganisms such as fungi and bacteria (biotic stress). The on-going change in climate conditions due to mostly anthropogenic causes such as the increase in $\mathrm{CO}_{2}$ emissions (Peters et al., 2011) exaggerates agricultural land deterioration due to temperature rise. This results in increased evapotranspiration, intensifying drought episodes (Zhao and Running, 2010) and increasing soil salinization, augmenting the $7 \%$ of the total and $30 \%$ of the irrigated agricultural land already affected by salinity (Munns and Tester, 2008). Available data and projections on the effect of climate change on pathogen spread are not conclusive, although the evidence points to increased reproductive potential and geographic expansion that will lead to interactions with both more hosts and different pathogen strains, increasing the chances for the rise of more virulent strains (Garrett et al., 2006). Therefore, the chances of plants encountering abiotic and/or biotic stress in the future are likely to be higher, with more frequent stress interactions.

Plants have developed a multitude of defense responses that allow them to adapt, survive and reproduce under stress conditions
(Pieterse et al., 2009). With the advancement of omics technologies and on-going functional characterizations of individual genes, it has become apparent that environmental adaptation is under tight regulation, which is critical for plant survival (López et al., 2008). Many components of this regulatory network are involved in responses to different stresses but may function antagonistically or some responses are prioritized over others, compromising plant resistance to multiple stresses simultaneously (Glazebrook, 2005; Yasuda et al., 2008).

Major components of the regulatory networks underlying environmental stress adaptation, pathogen recognition, and defense include reactive oxygen species (ROS) signaling (Miller etal., 2008), plant hormones (Bari and Jones, 2009; Peleg and Blumwald, 2011), changes in redox status (Munne-Bosch et al., 2013), and inorganic ion fluxes, such as $\mathrm{Ca}^{2+}$ (Martí et al., 2013). Based on omics data analyses these components appear to be at least partly shared between both abiotic and biotic stress signaling, indicating crosstalk and convergence of mechanisms in these pathways and the existence of a general stress response (Walley et al., 2007).

The nature of pathogen perception dictates that physical barriers such as the cuticle, stomata, and cell walls are also critical for 
timely pathogen recognition and interception (Asselbergh et al., 2007). As data generated by omics analyses derive from a mixture of different cell types and tissues, these spatially important interactions may be missed and these datasets may lead to erroneous conclusions about components shared and their significance in abiotic and biotic stress crosstalk. Moreover, as combinatorial stress potentially results in novel interactions between signaling components, extrapolation of results from studies with single stress conditions should be done with care.

Here we will elaborate on the mechanisms involved in adaptation and tolerance to combinatorial abiotic and biotic stress, with a focus on dehydration/salt stress and fungal and bacterial pathogens interaction. This review will particularly emphasize interactions that potentially arise during the pathogenesis timeline and were as yet given little attention. We will discuss molecular components with potentially critical roles in abiotic and biotic stress tolerance crosstalk, and propose breeding approaches toward effective crop improvement against combinatorial stress.

\section{EVIDENCE OF CROSSTALK EVIDENCE AT THE PHENOTYPIC AND PHYSIOLOGICAL LEVEL}

Studies on the commonly occurring combination of drought and heat stress have revealed that physiological and molecular responses of plants exposed to both stresses are markedly different from their response to the individual stresses (Rizhsky et al., 2004). Similarly, there are numerous reports about abiotic stress (mostly drought and salinity) affecting pathogen resistance, which is indicative of interaction between abiotic and biotic stress. There are reports of disease resistance attenuation by high humidity and high temperature (Wang et al., 2005, 2009). In most cases, abiotic stress predisposes plants to subsequent pathogen infection (Sanogo, 2004; Triky-Dotan et al., 2005; You et al., 2011), although positive effects on resistance to foliar pathogens have also been reported (Wiese et al., 2004; Achuo et al., 2006).

There is evidence that different levels of abiotic stress have a significantly different impact on disease susceptibility (Soliman and Kostandi, 1998; Desprez-Loustau et al., 2006). Salinity stress, in particular, exerts its damaging effect through both osmotic effects and ion toxicity resulting from ion accumulation (mainly $\mathrm{Na}^{+}$and $\mathrm{Cl}^{-}$). As $\mathrm{NaCl}$ is an antifungal agent (Blomberg and Adler, 1993) it could potentially exert a direct toxic effect on fungal growth after accumulation inside the plants (Figure 1). In line with this argument are the many examples of reduction of fungal pathogenicity by metal accumulation (Poschenrieder et al., 2006; Fones et al., 2010), and a similar trend is observed for $\mathrm{NaCl}$ accumulation (Soliman and Kostandi, 1998). Therefore salt stress-pathogen interactions may be highly influenced by stress intensity, which affects the degree of accumulation of salt in the plant. The different tolerance strategies of the host against ion toxicity (ion exclusion at the roots and/or ion compartmentalization in the above ground organs inside the vacuoles) can impact on the outcome of plant-pathogen interactions under salt stress. Therefore, it appears that the outcome of the interaction in most occasions is plant, genotype, pathogen, and stress intensity dependent. Moreover abiotic stress, except for potentially dampening or strengthening signaling responses for pathogen defense deployment, could create more or less favorable conditions for pathogen growth by additionally influencing the physiological status of the plant such as water and ion content.

Vice versa, plant responses to abiotic stress can be affected by prior interactions with pathogenic fungi. Pathogen infection has been shown to reduce photosynthesis and water use efficiency (WUE) and induce abnormal stomata opening patterns, and all of these are critical for plant tolerance to abiotic stress (Bilgin et al., 2010; Grimmer et al., 2012). Salicylic acid (SA) signaling, induced after infection with biotrophic fungi, can attenuate abscisic acid (ABA) signaling that is orchestrating plant adaptive responses to abiotic stress (Kim et al., 2011b). Infection by a root pathogen was shown to increase shoot $\mathrm{Na}^{+}$and $\mathrm{Cl}^{-}$content under saline conditions in Phaseolus vulgaris (You et al., 2011; Figure 1). Finally genetically heightened resistance to pathogens is often accompanied by a fitness cost that may generally affect the plant performance under both abiotic stress and stress-free conditions (Huang etal., 2010; Todesco et al., 2010).

A direct interaction of pathogen virulence factors with stress tolerance components of the plant host was demonstrated for the Pseudomonas syringae type III effector HopAM1 that targets HSP70 (Jelenska et al., 2010) involved in heat tolerance and stomata closure under stress (Clement et al., 2011). Overexpression of HopAM1 in Arabidopsis thaliana results in increased sensitivity to ABA and salt stress, providing proof of direct manipulation of abiotic stress signaling components (Goel et al., 2008).

Interaction of plants with microorganisms can also be beneficial to abiotic tress tolerance. For instance, infection of plants with RNA viruses improved tolerance to drought (Xu et al., 2008). Infection with the vascular pathogen Verticillium spp. increased Arabidopsis thaliana drought tolerance due to de novo xylem formation, which enhances water flow (Reusche et al., 2012). Symbiosis with fungal endophytes (Marquez et al., 2007) as well as association of plant roots with non-pathogenic rhizobacteria and mycorrhizal fungi increases plant vigor under stress conditions through, among others, interactions with hormonal pathways and the sustainment of water and source-sink relations (Dodd and Perez-Alfocea, 2012). Remarkably, rhizobacteria colonization is also shown to enhance plant resistance to fungal pathogens and insects, via systemic signaling that triggers immunity (induced systemic resistance, ISR; Berendsen et al., 2012).

Further evidence for abiotic and biotic stress resistance crosstalk comes from studies of the effects of exogenous application of chemicals that sensitize plant defense responses, a phenomenon called priming (Goellner and Conrath, 2008). For example, application in Arabidopsis thaliana of $\beta$-aminobutyric acid ( $\beta$-ABA), a non-protein amino acid, results in enhanced resistance to a wide range of stresses including heat, drought, and salinity stress, as well as enhanced resistance to biotrophic as well as necrotrophic fungi (Ton et al., 2005). Exogenous application of SA renders many crop plants more tolerant to an extensive array of abiotic stresses (Horváth et al., 2007), and similar observations have also been reported after treatment with jasmonates (Walia et al., 2007). 


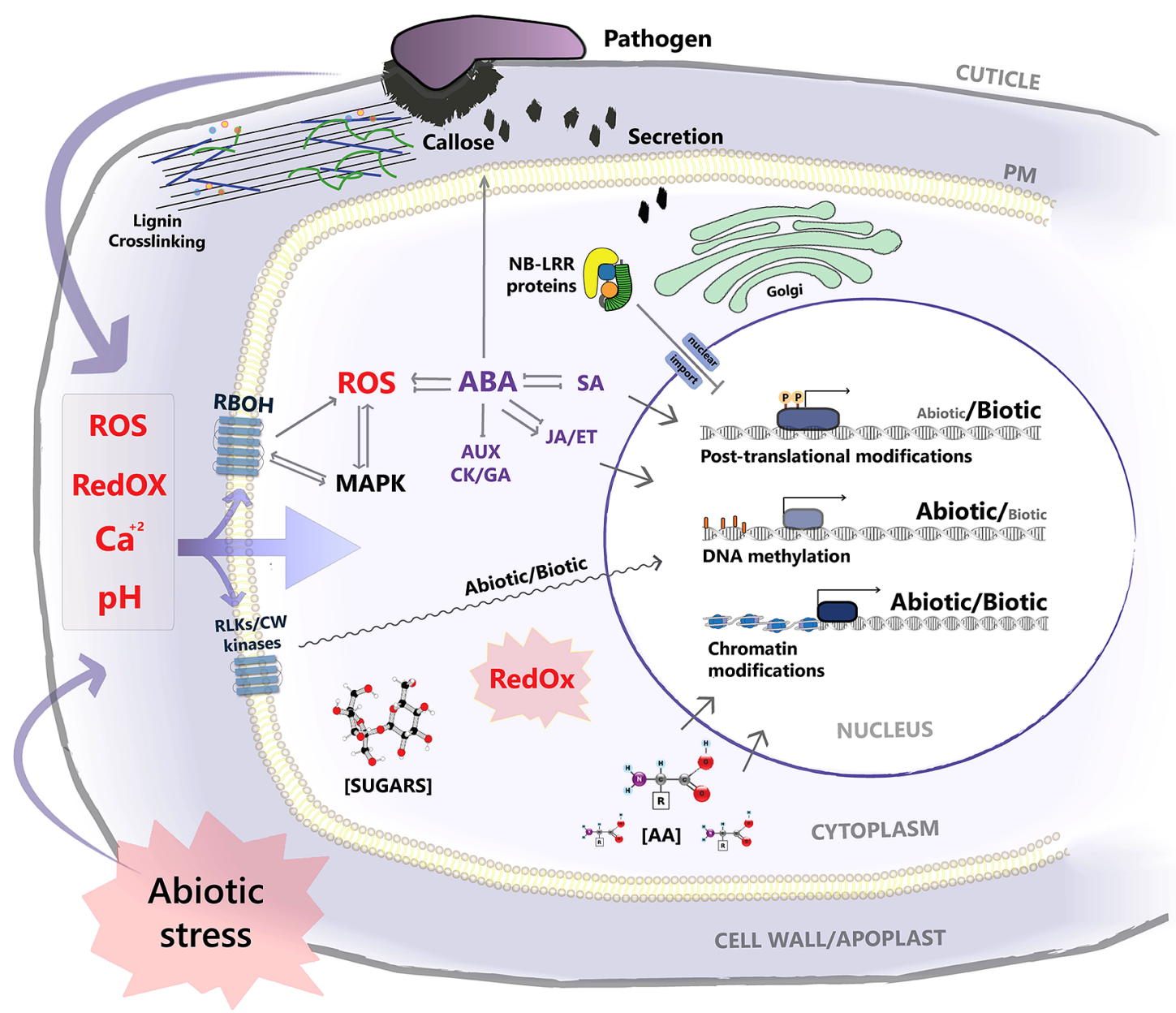

FIGURE 1 | A scheme for the interaction interface and overlapping signaling pathways of abiotic and biotic stress at the cellular level. Both stress factors affect the homeostasis of chemical signals at the apoplastic space such as $\mathrm{Ca}^{2+}, \mathrm{ROS}$, and $\mathrm{pH}$ levels. Abiotic stress potentially affects the structure and properties of preformed and inducible physical barriers that function against pathogen penetration. Signaling nodes such as RBOHs and RLKs and other cell wall (CW) kinases localized at the plasma membrane, and MAPKs are shared by both stressors, with downstream signal specificity under stress combination remaining elusive. ABA signaling, central for adaptation to abiotic stress, negatively impinges on defense hormone signaling, while, pathogen dependent, positive interactions are observed for JA signaling. ABA-SA interaction is two sided, as activation of SA signaling by pathogen challenge attenuates $A B A$ responses. ABA positively contributes to pre-invasion defense, enhancing callose deposition. Rewiring of secretory machinery under abiotic stress potentially affects its function in the exocytosis of antimicrobial compounds at the site of infection. Nuclear translocation of R-genes is negatively affected under abiotic stress. Redox state, as well as metabolite concentration such as sugars and amino acids (AA), function as drivers for post-translational modifications, modulating the activity of target proteins/transcription factors. Previously/simultaneously encountered stress effect on chromatin and DNA methylation status, potentially impacts on expression patterns of the recipient genes under stress combination. Transcription factor activation and binding to stress responsive gene promoters is a convergence point regulating the signal output under combinatorial stress with diverse outcomes.

\section{EVIDENCE FOR CROSSTALK FROM WHOLE GENOME EXPRESSION ANALYSES}

Evidence for regulatory crosstalk between abiotic and biotic stress response at the molecular level comes mostly from observations of expression patterns of genes under independent imposition of the single stress conditions. In Arabidopsis thaliana, a significant number of genes up-regulated by salinity stress are also induced in response to biotic stresses (Ma et al., 2006). Whole genome expression meta-analysis experiments under different abiotic and biotic stress treatments revealed a significant number of genes that are commonly regulated under abiotic and biotic stress conditions (Ma and Bohnert, 2007; Shaik and Ramakrishna, 2013, 2014).
Functional categories enriched in the 197 commonly regulated genes identified by ( $\mathrm{Ma}$ and Bohnert, 2007) include response to ABA, SA, jasmonic acid (JA), and ethylene (ET), major stress hormones controlling adaptation to abiotic and biotic stress. Several members of signaling pathways involving mitogen-activated protein kinase (MAPK), $\mathrm{Ca}^{2+}$, ROS, phospholipids, mitochondrial functions, vesicle trafficking, and apoptosis were induced under biotic as well as abiotic stresses (Ma and Bohnert, 2007). Transcription factors (TFs) appear to be major orchestrators of stress crosstalk with members of WRKY, MYB, ERF, NAC, and HSF displaying similar induction patterns across stress treatments (Ma and Bohnert, 2007; Shaik and Ramakrishna, 2013). 
On the other hand, another study using co-expression data to identify cis-regulatory elements (CREs) of stress responses identified distinct CREs for the response to abiotic and biotic stressors (Zou et al., 2011). In addition, a number of CREs identified for both types of stress appear to oppositely regulate the expression of downstream genes in response to abiotic or biotic stress.

A different approach, yeast two-hybrid assays targeting major regulators of rice abiotic and biotic stress response, identified proteins that are present in multiple interactomes (Seo et al., 2011; Sharma et al., 2013). These include OsMPK5, the wall-associated kinase 25 (WAK25), sucrose non-fermenting-1-related protein kinase-1 (SnRK1), and WRKY family TFs.

Recently, examination of the transcriptional response of different Arabidopsis thaliana accessions to combinations of abiotic and biotic stressors revealed that across the treatments on average $60 \%$ of expression changes under combinatorial stress could not be predicted by the changes in response to the individual stresses (Rasmussen etal., 2013). The functional categories enriched in the affected genes were similar to those discovered after transcriptome meta-analyses of individual stressors, i.e., stress hormone responses, ROS, and MAPK signaling and regulation of hypersensitivity response. The response of many of these transcripts was canceled or prioritized under stress combination in comparison with the individual stress pointing to potential antagonistic interactions with detrimental effects on plant adaptation under combinatorial stress. In a similar study, the increased susceptibility to a virus after simultaneous application of drought and heat stress was accompanied by down regulation of pathogenesis-related (PR) genes and R-genes, which were otherwise induced under single viral stress (Prasch and Sonnewald, 2013). This indicates a direct negative effect of abiotic stress on major defense executors, that adds up to the antagonistic regulation observed in other signaling pathways. These studies clearly emphasize that even though regulatory pathways overlap between stresses, combinatorial stress needs to be treated and studied as a unique condition. Further functional characterization of individual gene members playing key roles in these pathways is required to extract meaningful conclusions.

\section{ABIOTIC-BIOTIC STRESS INTERACTION INTERFACE}

As mentioned above, abiotic and biotic stress interactions can occur at multiple levels, depending on the type of the stress (osmotic, ionic), the lifestyle, and infection strategy of the pathogen (biotroph/necrotroph, infection by direct penetration/through stomata, etc.) as well as the pathogenesis stage. We will summarize molecular components that according to evidence mentioned above participate in stress crosstalk. We will follow the pathogenesis timeline highlighting first extracellular interactions taking place at the epidermis and the apoplast during the initial stages of pathogenesis and moving on to the interactions in the intracellular environment during pathogen colonization (Figure 2). As information under combined stress is limited, and a detailed coverage of all potential interactions is not possible, our intention is to provide leads for future research that will aid to further dissect plant adaptive responses and tolerance under combined abiotic and biotic stress.

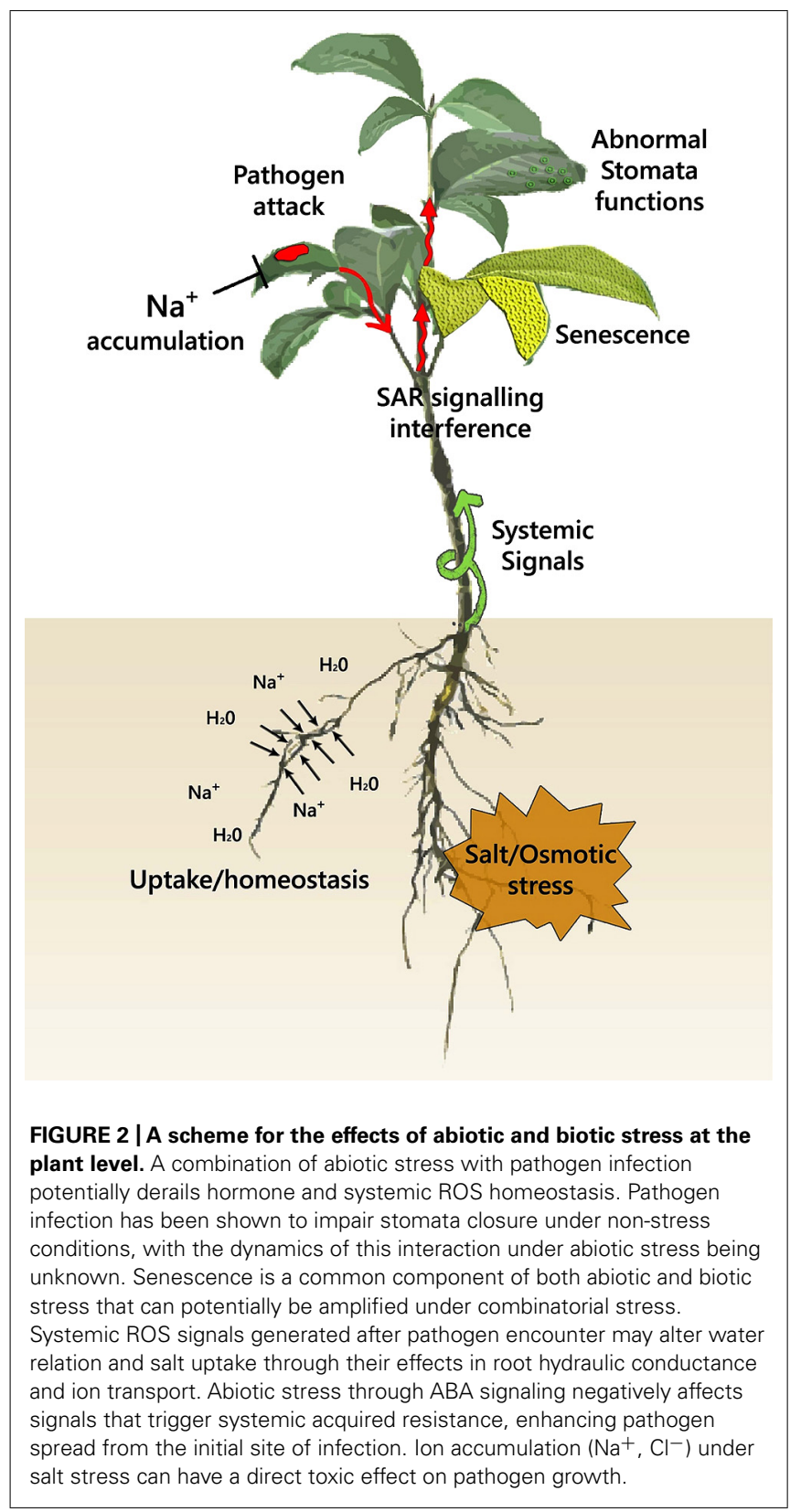

\section{EXTRACELLULAR INTERFACE Cuticular layer}

The cuticle and cell wall constitute the first layers of defense against microbial attackers. They not only serve as physical barriers against pathogen penetration, but also as sensitive sensors for the timely activation of the intracellular and systemic defense responses. Arabidopsis thaliana mutants in long-chain acyl-CoA synthetase 2 (LACS2), a gene that is involved in cuticle biosynthesis, exhibit increased permeability of the cuticular layer which leads to increased resistance to Botrytis cinerea (Bessire et al., 2007). Interestingly, ABA deficiency causes similar cuticular defects and heightened resistance to $B$. cinerea through faster induction of defense responses and $\mathrm{H}_{2} \mathrm{O}_{2}$ production both in Arabidopsis and tomato, indicating a link between abiotic stress 
signaling, cuticle structure and defense responses (Curvers et al., 2010). In the study by Xiao et al. (2004), however, lacs2 Arabidopsis mutants show no alteration in the resistance against the necrotroph Alternaria brassicicola and biotrophs, and even increased susceptibility against $P$. syringae. The latter observation points to a positive contribution of a thicker cuticle to resistance against $P$. syringae, indicating that the effects may be pathogenspecific (Tang etal., 2007). The well-documented increase in cuticular thickness under conditions of water deficiency (Kosma etal., 2009) may thus result in alteration in the deployment of the pathogen defense response. The cuticle does appear to be a sensor of the osmotic status and to be essential for the upregulation of ABA biosynthesis genes under osmotic stress (Wang et al., 2011) through a yet not clearly defined mechanism; cuticle disruption by pathogens may therefore affect osmotic stress acclimation.

\section{Cell wall-apoplastic space}

Cell walls similarly appear to be an integrated signaling component for the defense against pathogens. Changes in pectin properties and composition in the Arabidopsis powdery mildew-resistant (pmr) mutants pmr5 and pmr6 resulted in a SA, JA, and ET independent increase in resistance to powdery mildew species (Vogel et al., 2004). Cellulose deficiency caused either by non-functional cellulose synthase genes or by chemical treatment enhances the synthesis of the defense hormones SA, JA, and ET and signaling and results in increased resistance to pathogens (Hématy et al., 2009). Intriguingly, these responses were attenuated when plants were grown under high osmotic pressure which reduced the turgor pressure (Hamann etal., 2009), suggesting that the defense response may be initiated by sensing the increased turgor pressure as a result of cell wall weakening. Osmotic stress, which is a common component of many abiotic stresses, may therefore interfere with the ability of plants to sense damage to the cell wall, due to already reduced turgor, resulting in inadequate activation of defense mechanisms.

The above-mentioned alterations in plant pathogen interactions in cell wall component biosynthesis mutants may be the consequence of the erroneous activation of integral receptor proteins such as RLKs and RLPs (receptor-like kinases and receptorlike proteins, respectively) which survey the cell wall integrity and bind to MAMPs and DAMPs (microbial- and damage-associated molecular patterns, respectively). Upon activation these transmembrane proteins (e.g., the RLK family WAK), send signals for the elicitation of downstream defense responses. Changes of cell wall structure and adherence to the plasma membrane upon exposure to abiotic stresses may affect their functional integrity. This is emphasized by the observation that NDR1, an essential component of disease resistance mediated by CC-NB-LRR genes (McHale et al., 2006), is functioning in cell wall-plasma membrane adhesion. Down-regulation of NDR1 resulted in alterations in the cell wall-plasma membrane interaction and compromised resistance to virulent P. syringae (Knepper et al., 2011). Abiotic stress may also affect the abundance of cell wall receptors by influencing their transcript levels. THE1 is a member of the CrRLK1L RLK family that is involved in cell wall damage sensing and subsequent control of the downstream accumulation of ROS, and its expression is down-regulated under abiotic stress but up-regulated after pathogen challenge (Lindner et al., 2012), while similar expression patterns are observed for the WAK gene family (Shaik and Ramakrishna, 2013).

Pathogen recognition activates a battery of defense responses that target the apoplastic space. These include local cell wall enforcement, secretion of antifungal compounds at the site of intended penetration and up-regulation of enzymes with fungal cell wall degrading activities (Van Loon et al., 2006). These events are characterized and regulated by signature changes in $\mathrm{pH}, \mathrm{ROS}$ homeostasis, and the redox state. Simultaneous exposure to abiotic stress can potentially impinge on the generation and decoding of these signatures, affecting subsequent responses. For example, apoplastic $\mathrm{pH}$ is transiently decreased following fungal infection (Felle etal., 2004), while an increase in $\mathrm{pH}$ is observed under salt stress (Geilfus and Muhling, 2011). Moreover the downregulation of cell wall peroxidases under abiotic stress (Shaik and Ramakrishna, 2014) can potentially dampen the production of ROS signatures that trigger defense responses (Daudi et al., 2012). Physical barriers enforcement after pathogen encounter through crosslinking of lignin monomers by ROS, which are produced by apoplastic peroxidases, NADPH oxidases and germin-like proteins, prevent pathogen penetration. Lignin content was found to be reduced under mild drought conditions to facilitate the maintenance of growth under conditions of decreased turgor pressure (Vincent et al., 2005), but severe stress resulted in increased lignin content (Lee et al., 2007). These findings may provide insight on the mechanisms leading to differential responses under combined stress across different abiotic stress intensities.

\section{Vesicular trafficking and callose deposition}

Another form of inducible defense response at the site of penetration is the formation of papillae that contain callose, antimicrobial secondary metabolites such as phenolic compounds, and ROS. Antimicrobial compounds are accumulating through vesicles originating from cellular compartments, such as the Golgi apparatus, which become polarized toward the site of infection (Underwood and Somerville, 2008). The significance of vesicle-mediated secretion in plant immunity has been demonstrated by the discovery of mutants defective in exocytosis of vesicles (with mutations in SNARE complex proteins $H v$ ROR2 and AtPEN1), which display diminished penetration resistance to powdery mildew pathogens (Collins et al., 2003). Vesicular trafficking appears to be rewired in an opposite way under salt stress, as vesicles containing $\mathrm{Na}^{+}$are fused with the central vacuole to maximize compartmentalization of $\mathrm{Na}^{+}$(Hamaji et al., 2009). Interestingly, knockout of different SNARE proteins resulted in increased salt tolerance (Hamaji et al., 2009), indicating possible antagonistic interactions of salt stress and pathogen infection at the level of vesicle trafficking, although further comprehensive experiments are required to substantiate this hypothesis.

Callose is a $\beta-1,3$-glucan polymer that is deposited at the sites of attempted fungal penetration in the form of papillae. It is an important inducible defense mechanism, with enhanced deposition being observed after exogenous application of priming 
chemicals like $\beta$-ABA. A mutant screen for plants defective in $\beta$-ABA-induced priming identified among others mutants in the ABA biosynthesis gene zeaxanthin epoxidase (ABA1; Ton et al., 2005). These mutants failed to exhibit both $\beta$-ABA-induced callose deposition against $H$. parasitica and increased tolerance to salt stress, thereby providing a link between the induction of abiotic and biotic stress responses by $\beta$-ABA. In accordance with these observations the callose-mediated increased resistance of the ocp 3 Arabidopsis mutant to necrotrophic pathogens requires ABA (Garcia-Andrade et al., 2011). Moreover ocp3 mutants accumulate higher levels of ABA, and are more drought tolerant (Ramírez et al., 2009). Therefore ocp3, a homeodomain TF, appears to be a convergence point for $\mathrm{ABA}$ and callose regulation that can be manipulated to enhance resistance under combinatorial stress.

Callose accumulation appears to be a point of convergence of abiotic and biotic signaling as variability in environmental conditions, which affect the redox state of the plant, such as light intensity, have a significant impact on the magnitude of callose deposition after pathogen elicitation (Luna et al., 2011). As callose deposition is a major component of the pre-invasion defense of plants (Ellinger etal., 2013), detailed characterization of the regulation of callose accumulation under simultaneous abiotic stress may be invaluable in building combined stress tolerance in crops.

\section{INTRACELLULAR SIGNALING INTERACTIONS Interconnections between $\mathrm{Ca}^{2+}$ and ROS signaling}

Changes in calcium fluxes and production of ROS are among the earliest plant responses to abiotic stress and pathogen challenge. The decoding of both signals relies on "signature" spatiotemporal patterns and oscillations specific to the stress encountered (Dodd et al., 2010; Mittler et al., 2011). Moreover, both components are highly interconnected: $\mathrm{Ca}^{2+}$ signaling components such as calmodulins (CaMs) and calcium-dependent protein kinases (CDPKs) regulate ROS production by NADPH-oxidases (Takahashi et al., 2011). ROS vice versa affect $\mathrm{Ca}^{2+}$ signaling through regulation of $\mathrm{Ca}^{2+}$ permeable channels (Demidchik et al., 2007). It is plausible that there are either unique signatures for combinations of stresses, or that there is interference between the abovementioned signals that potentially dampens or strengthens the downstream responses.

Whole genome expression analyses coupled with promoter motif identification provided further evidence that $\mathrm{Ca}^{2+}$ orchestrates the early responses to both biotic and abiotic stress as the overrepresented motif "CGCGTT" identified in the promoters of the commonly regulated genes, contains the core "CGCG" $\mathrm{Ca}^{2+}$ responsive cis-element (Walley et al., 2007). The investigation of mutants defective in the induction of a hypersensitive response after pathogen infection has led to the identification of genes encoding for cyclic nucleotide gated channels (CNGCs) which are non-selective cation transporters (Clough et al., 2000). members of which are also involved in salt and heat stress tolerance through regulation of $\mathrm{Ca}^{2+}$ fluxes (Guo et al., 2010; Finka et al., 2012). Furthermore, $\mathrm{Ca}^{2+}$ downstream signaling components have been shown to mediate responses to both abiotic and biotic stress stimuli. The CAMTA3 TF is important for cold acclimation of Arabidopsis by stimulating the expression of CBF1, CBF2, and ZAT12 that are also involved in adaptation to dehydration and oxidative stress (Doherty et al., 2009). Moreover, CAMTA3 negatively regulates SA accumulation and plant defenses through CaM binding (Du etal., 2009). Other proteins interacting with CaM include TF families like NAM, WRKY, and MYB (Popescu et al., 2007) many members of which are involved in abiotic and biotic stress crosstalk.

CDPKs have a unique feature to both bind calcium and functionally decode the message by target protein phosphorylation. They appear to represent a central node in the regulation of abiotic and biotic stress responses (Schulz et al., 2013). For example, Arabidopsis CPK4 and CPK11 positively regulate ABA responses and their down-regulation renders plants salt-sensitive (Zhu et al., 2007), and are important for the oxidative burst and defense responses (Boudsocq et al., 2010). In addition, CDPKs regulate $\mathrm{ROS}$ production through phosphorylation-mediated regulation of RBOH activity (Dubiella et al., 2013). StCDPK4- and StCDPK5-mediated phosphorylation increases the activity of StR$\mathrm{BOHs}$ and the increased ROS production results in a stronger hypersensitivity response after pathogen challenge, favoring resistance against biotrophic pathogens but compromising resistance against necrotrophic fungi (Kobayashi et al., 2012). Recently, the CDPK OsCPK12 was shown to increase salt stress tolerance and decrease blast disease resistance in rice through reduced ROS production as a result of down-regulation of $\mathrm{RBOH}$ expression, enhanced expression of antioxidant genes such as APX (ascorbate peroxidase), and increased sensitivity to ABA (Asano et al., 2012).

Dissecting the spatiotemporal and molecular specificity of $\mathrm{Ca}^{2+}$ and ROS signaling components is crucial for determining their precise functions in stress responses (Baxter et al., 2014), as is elegantly demonstrated by the identification of different $\mathrm{Ca}^{2+}$ binding affinities regulating the activation of two soybean CaMs (Gifford et al., 2013).

\section{Signal relay by MAPKs}

Mitogen-activated protein kinases are centrally positioned in $\mathrm{Ca}^{2+}-\mathrm{ROS}$ crosstalk and regulation as well as in the signal output after stress exposure. MAPK signaling cascades are relayed through MAPK kinase kinases (MAP3Ks) and MAPK kinases (MAP2Ks). Hydrogen peroxide $\left(\mathrm{H}_{2} \mathrm{O}_{2}\right)$ has been shown to mediate activation of the three major and well-studied Arabidopsis MAPKs, MAPK3, 4, and 6, through MAP3Ks and other kinases (Rentel et al., 2004; Teige et al., 2004). These MAPKs appear to have an overlapping function in signal transduction upon abiotic stress and pathogen challenge. Activation of Arabidopsis MAPK3 and MAPK6 as well as their homologs in tobacco WIPK and SIPK (Segonzac et al., 2011) after PAMP recognition is essential for fungal and bacterial resistance (Asai et al., 2002). The importance of MAPK3 and MAPK6 in plant immune responses is highlighted by the discovery that the $P$. syringae effector HopAI1 directly interacts and inactivates both, promoting virulence (Zhang et al., 2007). Additionally MAPK6 is directly involved in regulating ET biosynthesis in Arabidopsis by activation through phosphorylation of ACS2 and ACS6, which results in an increase in ET biosynthesis (Liu and Zhang, 2004). MAPK4 acts as a negative regulator of defense responses and 
SA accumulation by phosphorylating MEKK2, a MAP3K protein (Kong et al., 2012).

On the other hand, down-regulation of MAPK3 resulted in altered stomata opening patterns in response to $\mathrm{ABA}$ and $\mathrm{H}_{2} \mathrm{O}_{2}$ in Arabidopsis (Gudesblat et al., 2007). Moreover, the ABA-induced expression of AtCAT1, which is involved in $\mathrm{H}_{2} \mathrm{O}_{2}$ homeostasis, is controlled by an AtMKK1-AtMAPK6 signaling cascade (Xing et al., 2008). Constitutive activation of AtMAPK4 and AtMAPK6 rendered plants more tolerant to cold and salt stress (Teige et al., 2004) and CAT2 and tAPX, which are involved in $\mathrm{H}_{2} \mathrm{O}_{2}$ regulation, appear to be regulated by AtMAPK4 (Pitzschke et al., 2009). In rice, OsMAPK5 appears to be a convergence point of abiotic and biotic stress responses, as its silencing results in sensitized defense responses and resistance to fungal and bacterial pathogens at the expense of salt and drought tolerance (Xiong and Yang, 2003).

These examples emphasize the complexity of MAPK-mediated defense signaling with diverse and sometimes overlapping functions of different members of the signaling pathway. Downstream targets of MAPK6 overlapped 60\% with MAPK3 targets, while a $50 \%$ overlap was observed between MAPK3 and MAPK4 targets (Popescu et al., 2009). Probably, the one-dimensional overlap can be resolved by multidimensional regulation, such as different spatiotemporal transcription and protein subcellular localization, activation thresholds, feedback loops with phosphatases and scaffolding (Tena etal., 2011; Samajova et al., 2013). Many of the above-mentioned components appear to be an integral part of broad stress tolerance priming by exogenous application of chemicals (Beckers et al., 2009; Xia et al., 2009), and the detailed study of MAPK activation, localization, and substrate affinity under these conditions can increase our understanding of plant responses under stress combinations.

\section{Hormone signaling}

Plant hormones are central to the integration of environmental stimuli in the coordination of growth under optimal and stress conditions, including the regulation of defense responses after pathogen attack. Plant hormones do not act independently, and extensive synergistic or antagonistic interaction between hormonal pathways is observed in development and stress responses after exogenous application, or through mutant analysis (Wolters and Jurgens, 2009). Transcriptomic studies have aided in unveiling these interactions (Nemhauser et al., 2006), and it was recently shown that hormonal pathways can be directly connected with each other by protein-protein interactions between their signaling components (Hou et al., 2010; Zhu et al., 2011).

Abscisic acid is the major hormone that positively contributes to adaptation to osmotic stress, a major component of several abiotic stresses. Its involvement in the regulation of defense responses has been a topic of recent comprehensive reviews (Asselbergh et al., 2008; Ton et al., 2009). The consensus is that ABA negatively regulates defense responses against both biotrophic and necrotrophic pathogens through negative interactions with $\mathrm{SA}$ and JA/ET biosynthesis and signaling; ABA biosynthesis mutations show sensitization of these signaling pathways after pathogen challenge (Achuo etal., 2006; De Torres Zabala et al., 2009; Sanchez-Vallet et al., 2012). Comprehensive analyses of
ABA-deficient mutants revealed further pleiotropic alterations that may be part of ABA-defense crosstalk such as reduced cuticle thickness and sensitized $\mathrm{H}_{2} \mathrm{O}_{2}$ production in response to $B$. cinerea in tomato (Asselbergh et al., 2007) and altered cell wall composition in Arabidopsis (Sanchez-Vallet et al., 2012). Moreover ABA compromised a chemically induced systemic acquired resistance (SAR) through suppression of SA biosynthesis in Arabidopsis, while genetically enhanced ABA catabolism reversed this effect (Yasuda et al., 2008).

Nevertheless, ABA signaling can positively contribute to preinvasive defense responses and to early defense signaling against certain necrotrophic pathogens (Adie et al., 2007). ABA positively contributes to resistance against pathogens that infect through stomata, such as P. syringae (Melotto et al., 2006), as well as to other pre-invasion defense mechanisms such as callose deposition (Ton and Mauch-Mani, 2004; Adie et al., 2007; Garcia-Andrade et al., 2011).

Identification of downstream regulatory nodes that channel interactions between hormonal pathways is of great importance in fine-tuning resistance to both abiotic and biotic stress. Besides TFs, which will be discussed in a following section, other regulators of the transcriptional machinery have been uncovered to function in stress crosstalk. RNA chaperones such as RNA helicases are shown to regulate transcription in response to various stressors (Li et al., 2008; Mazzucotelli et al., 2008). MED25, a subunit of the mediator complex which is a component of the transcriptional machinery, is involved in the antagonistic crosstalk between ABA and JA (Chen et al., 2012). In a recent report, the Arabidopsis pathogenesis-related protein 2 (PR2), which encodes $\beta$-1,3-glucanase involved in callose degradation, was shown to be down regulated in response to ABA, partly elucidating ABA-mediated capacitation of callose deposition. The ahg2-1 mutant in Arabidopsis accumulates both ABA and SA and has increased expression of defense related genes, which is an indication that ABA and SA do not always act antagonistically. Transcriptome analysis of the ahg2-1 mutant revealed complex interactions between $\mathrm{ABA}$ and SA signaling involving altered mitochondrial and RNA metabolism (Nishimura etal., 2009), highlighting multilevel connections between the two signaling pathways that add to the complexity and hinder straightforward conclusions.

Recent research has highlighted the direct involvement of the growth hormones gibberellin, cytokinin, auxin, and brassinosteroid in responses to adverse growth conditions and pathogen attack (Robert-Seilaniantz et al., 2011). For example, GA signaling directly regulates JA signaling, mediated through direct binding of the GA repressor protein DELLA to JAZ proteins and relieving JA signaling repression (Hou et al., 2010). DELLA proteins appear to be central nodes in abiotic and biotic stress cross-talk. ABA and ET signaling promote DELLA stabilization which positively affects ROS detoxification (beneficial for acclimation to abiotic stress) through higher expression of ROS detoxification genes (Achard et al., 2008). DELLAs also sensitize JA signaling (through binding of DELLAs to JAZ) at the expense of SA signaling, enhancing resistance to necrotrophic pathogens (Navarro et al., 2008). This may provide an explanation for the often-observed positive correlation between resistance to abiotic stress and resistance to 
necrotrophs (Navarro et al., 2008; Abuqamar et al., 2009; Ramírez et al., 2009).

Cytokinins were shown to positively regulate defense responses to biotrophic pathogens (Argueso et al., 2012) via SA accumulation, and increased defense gene expression through interaction of the cytokinin response regulator ARR2 with TGA3, a TF central for defense gene activation (Choi et al., 2010). This suggests that the increased cytokinin catabolism observed under abiotic stress-induced senescence may potentially contribute to further down-regulation of SA responses and increased susceptibility to biotrophic pathogens.

The roles of auxin and brassinosteroids in stress responses and their potential participation in stress crosstalk remains elusive. Auxin signaling shows antagonistic crosstalk with SA (Wang et al., 2007), although auxin contributes to reduced senescence (Kim et al., 2011a) which may be of great importance under exposure to a stress combination. Brassinosteroid (BR) signaling positively affects abiotic stress tolerance, as is evident by both BR exogenous application (Divi et al., 2010) and genetic de-repression of the BR signaling pathway (Koh et al., 2007). BR signaling probably interacts synergistically with ABA signaling and stimulates ROS detoxification (Divi et al., 2010). BR's involvement in defense signaling is rather complicated. In tobacco and rice exogenous application of BRs appeared to clearly enhance resistance to a wide range of pathogens (Nakashita et al., 2003). Similar results were obtained in cucumber, which showed heightened resistance to Fusarium oxysporum as a result of activated production of $\mathrm{H}_{2} \mathrm{O}_{2}$ by NADPH oxidase and expression of defense related genes ( $\mathrm{Li}$ et al., 2013). On the contrary BRs appear to be negatively regulating resistance to the root-infecting oomycete Pythium graminicola by antagonizing SA and GA related defense responses (De Vleesschauwer etal., 2012). BR signaling shares LRR-RLK and BAK1 proteins with PAMP immune signaling (Chinchilla et al., 2009). Contradictory effects of BR signaling on immune responses have been recently reported in Arabidopsis (Albrecht et al., 2012; Belkhadir et al., 2012; Lin et al., 2013), which require further study.

It is clear that hormonal crosstalk is extensive and occurs in multiple combinations. Further understanding of plant responses under combined stress exposure is required to dissect the multilevel responses under these conditions. As an example of the underlying complexity, both drought stress and exogenous ABA application result in an increased endogenous ABA content in tomato, but they differentially affect resistance to powdery mildew and Botrytis, with drought enhancing and ABA application compromising resistance (Achuo et al., 2006). Notably the ABA-deficient tomato mutant sitiens exhibited increased resistance similar to the effect of drought (Achuo et al., 2006). The complexity of interactions under abiotic stress is further emphasized by transcriptome analyses under abiotic stress in which up-regulation of a significant number of JA/ET-responsive genes and accumulation of their transcripts was observed (Walia et al., 2007; Huang etal., 2008). Besides the effects of direct hormonal interactions on abiotic and biotic stress tolerance mechanisms additional indirect interactions should be considered, such as the alteration of developmental programs and the regulation of senescence which may be critical for evolutionary species fitness and yield performance in crop plants (Wu et al., 2012a).

\section{Cellular redox state}

The cellular redox state is the sum of reducing and oxidizing redox-active molecules (Potters et al., 2010) and it acts both as a sensor of environmental perturbations (as most of them impose oxidative stress) and as a buffer against these perturbations to maintain cellular homeostasis. It acts as a central integrator of ROS, energy and metabolic regulation under stress as well as optimal conditions. Its major constituents are ascorbate, glutathione $(\mathrm{GSH}), \mathrm{NADP}(\mathrm{H})$, small proteins acting as antioxidants like thioredoxin and glutaredoxins as well as many diverse metabolites such phenolics, amino acids, carotenoids, and tocopherols. The cellular redox state is dependent on both their accumulation and their reduction-oxidation state (Potters et al., 2010). Genetic manipulation of redox homeostasis results in altered hormone homeostasis and responses to pathogens and abiotic stresses (Mhamdi et al., 2010), exemplifying its significance. As abiotic and biotic stress commonly impinge on the redox status (albeit not in a similar manner; Foyer and Noctor, 2005), redox homeostasis is potentially a central orchestrator of the phenotypic response to stress combinations. Redox perturbations after imposition of a stress factor may affect responses to subsequent challenges by additional stressors, thereby shaping the response to combined stresses. For example, a transient increase in GSH content drives the antagonistic crosstalk between SA and JA signaling (Koornneef et al., 2008) and GSH oxidation appears to drive the induction of both SA and JA pathways (Mhamdi et al., 2013).

Plant hormone signaling can directly perturb the redox status by modifying the expression and activities of antioxidant enzymes. ABA induces the expression of catalase, activating also at the same time the production of the ROS hydrogen peroxide through AtMAPK6 signaling (Xing et al., 2008). SA inhibits the function of catalase and cytosolic ascorbate peroxidase (Corina Vlot et al., 2009) and several glutathione transferases (Tian et al., 2012).

Programed cell death (PCD) is a plant response to developmental and environmental stimuli (e.g., in senescence) and pathogen defense (in the form of HR) that is initiated and regulated by redox changes, like an increased oxidation ratio of GSH and ascorbate (De Pinto et al., 2012). APX appears to be central in the redox regulation leading to PCD. Decreased activity of APX isoforms was observed in heat-induced PCD (Locato et al., 2009), and overexpression or down-regulation in Arabidopsis of a thAPX increased or decreased, respectively, sensitivity to NO-induced cell death (Tarantino etal., 2005). APX isoforms are also commonly upregulated under abiotic stress (Miller et al., 2008). Considering the important role of APX in the drought-heat stress interaction (Koussevitzky et al., 2008) it is of great interest to explore APX enzyme regulation under combinatorial stress.

Redox status changes can directly impact protein function through post-translational modifications. One pronounced example of post-translational modifications controlling protein activity and localization is the interplay of $S$-nitrosylation and thioredoxin-mediated reduction in the control of the oligomeric and monomeric state of NPR1 (Tada etal., 2008), a master 
regulator of SA-mediated defense responses and recently proposed as a SA receptor (Wu et al., 2012b). The function of many more proteins appears to be regulated by $S$-nitrosylation, among them AtRBOHD as mentioned above (Yun et al., 2011), SA binding protein 3 (SABP3), methionine adenosyltransferase 1, the metabolic enzymes glyceraldehyde 3-phosphate dehydrogenase (GAPDH) and glycine decarboxylase (GDC), as well as metacaspase 9 (Astier et al., 2011). Identification of the dynamics of post-translational modifications on these and newly identified proteins under various stress combinations will shed light on their significance for plant adaptation responses to these conditions.

NO was recently found to exhibit biphasic control over cell death triggered by pathogens and pro-oxidants in Arabidopsis. In initial stages $S$-nitrosothiol (SNO) accumulation results in enhanced and accelerated cell death (Yun et al., 2011). However, constitutively high SNO levels decreased cell death through $S$ nitrosylation-mediated reduction in AtRBOHD activity (Chen et al., 2009; Yun etal., 2011). This differential regulation might have implications in conditions of combined abiotic and biotic stress as both result in increased NO levels. At a certain plateau concentration of NO, signaling components may be desensitized or inversely regulated, as exemplified by AtRBOHD, with detrimental effects on stress acclimation.

Redox changes and post-translational modification appear to be integral in priming for stress tolerance after exogenous application of chemicals (Tanou et al., 2009). This provides a potential explanation of the mechanism of action of diverse chemicals in plant defense sensitization. $\mathrm{H}_{2} \mathrm{O}_{2}$ and $\mathrm{NO}$ priming for salt tolerance in citrus moderately increased the abundance of oxidized and $S$-nitrosylated proteins, which then remained relatively similar after the application of stress. Non-treated plants were more stress sensitive and exhibited increased protein carbonylation and oxidation (Tanou et al., 2012). As both compounds provide increased tolerance to both abiotic and biotic stress, further characterization including the timing and magnitude of these post-translational modifications under different stress treatments and under stress combination may help to better understand the redox changes leading to stress cross-tolerance.

\section{Metabolite homeostasis and signaling}

Metabolites are the end products of gene expression and protein activities and therefore are the penultimate regulatory component for the phenotypic expression under stress conditions. As metabolites can have multiple functions such as being energy carriers, structural molecules and redox regulators or exerting direct antimicrobial activity against pathogens, uncovering their regulation and homeostasis under combined stress is of great significance.

Adaptation to both abiotic and biotic stress impinges significantly on primary metabolism homeostasis. Synthesis of antimicrobial metabolites and defense proteins is energy demanding (Bolton, 2009), while abiotic stress potentially leads to energy deprivation as photosynthesis is reduced under abiotic stress (De Block et al., 2005). As a result, it is fair to assume that under stress combinations these strong antagonistic effects will result in disturbed energy balance. However, recent results challenge the carbohydrate deprivation notion under mild dehydration stress (Hummel et al., 2010) and further experimental data under combined stress are required for firm conclusions. More evidence that sugar homeostasis and signaling drives defense responses are demonstrated by the down regulation of cell wall invertases. This results in dampening of defense responses and increased susceptibility to pathogens as a result of decreased availability of carbohydrates to fuel the defense responses at the site of infection (Essmann et al., 2008). Cell wall invertases appear to be down regulated under abiotic stress (Wingler and Roitsch, 2008) and as the regulation of their activity is a convergence point of hormonal and sugar signals for stress tolerance and senescence progression (Wingler and Roitsch, 2008), fine tuning of their expression might be a focal point in enhancing combined stress tolerance. The metabolic status of the host is also crucial for pathogen growth as it appears that pathogens manipulate different aspects of plant metabolism to achieve optimal conditions for their growth (Chen et al., 2010a).

The significance of amino acid homeostasis for the induction and regulation of defense responses was recently highlighted (Zeier, 2013). Amino acids may function as precursors in hormone biosynthesis and affect the redox state through their chemical properties or as precursors of redox regulators such as GSH. Amino acid abundance can impact hormone signaling through conjugation-mediated regulation of hormone activity (Woldemariam et al., 2012). Amino acid concentration appears to be significantly perturbed by abiotic stress as is revealed by metabolomics studies (Obata and Fernie, 2012). On the other hand a direct link between amino acid abundance and activation of SA-induced defense responses was recently demonstrated with heat-shock factor HsfB1, the translation of which is initiated under conditions of phenylalanine starvation (PajerowskaMukhtar et al., 2012). Phenylalanine appears to be accumulated under abiotic stress conditions (Urano et al., 2009; Widodo et al., 2009) and its potential as a molecular switch between abiotic and biotic stress responses should be explored.

Metabolic alterations under abiotic stress include the accumulation of compounds such as the raffinose family oligosaccharides raffinose and galactinol and the amino acid proline. These exhibit osmoprotective and antioxidant functions and have been positively correlated with abiotic stress tolerance (Korn et al., 2010). Galactinol overproduction was recently associated with increased resistance to necrotrophic pathogens (Mi et al., 2008). Moreover, proline metabolic regulation at the site of pathogen infection is important for both HR deployment and containment, probably through modulation of ROS levels as shown by expression and functional studies of proline dehydrogenase (Senthil-Kumar and Mysore, 2012). Myo-inositol metabolic regulation appears to be a convergence point for abiotic and biotic stress responses. Myoinositol is accumulating under most abiotic stress conditions and is positively contributing to tolerance as a compatible solute (Tan et al., 2013). A negative relationship between myo-inositol accumulation and pathogen resistance and PCD initiation was found in Arabidopsis, with a positive correlation between myo-inositol depletion and increased SA production and cell death (Chaouch and Noctor, 2010). 
Analysis of mutants that exhibit qualitative and quantitative alterations in the accumulation of fatty acid metabolites demonstrated that fatty acids are not only structural components of the cellular membranes, but they also exert a multitude of signaling functions. Fatty acid release from the membranes after pathogen encounter triggers the defense response (Savchenko et al., 2010). Linolenic acid (18:3) is a precursor for the production of the major cellular signaling components JA and oxylipins (Reinbothe et al., 2009). A reduction of the levels of oleic acid (18:1) triggers constitutive defense responses that are independent of SA signaling (Kachroo et al., 2001), but dependent on NO production (Mandal et al., 2012). Fatty acid homeostasis is disturbed under abiotic stress, as membrane composition changes are vital for the maintenance of membrane rigidity and functionality. Dehydration stress is shown to result in a reduction in 18:3 and increase in 18:1 lipid levels (Upchurch, 2008), and increased 18:3 levels by FAD3 or FAD8 overexpression enhanced drought tolerance in tobacco (Zhang et al., 2005). Manipulation of fatty acid composition can provide further insight into their function under stress combination.

\section{Transcription factors}

Regulatory modules like MAPKs-based pathways and core hormone signaling modules control the expression of a vast number of genes and therefore their manipulation in most cases have severe pleiotropic effects. Identification of downstream regulators involved in abiotic and biotic stress crosstalk such as TFs is important for more targeted manipulation and adaptation of plants to multiple stresses. The appropriate fine-tuning of their expression is an important aspect toward translation of scientific knowledge in crop plant improvement (Kasuga et al., 2004).

Bioinformatics and functional analyses have demonstrated that TFs involved in stress crosstalk comprise a diverse collection of members of the largest TF families in plants, such as NAC, MYB, AP2/ERF, WRKY, and others, reflecting the complexity of the genetic regulatory networks underlying stress crosstalk (Atkinson and Urwin, 2012; Shaik and Ramakrishna, 2014). Many members of these families are involved in regulation of leaf senescence, an integral component of both abiotic and biotic stress (Breeze etal., 2011). Moreover, in most cases the TFs identified are stress hormone-regulated, and therefore potentially act as molecular switches for the fine-tuning of hormonal responses.

Characterization of the mechanism of action of the candidate TFs involved in stress crosstalk is of great importance. For example, a TF with positive contribution to both abiotic and biotic stress tolerance can be directly useful for breeding combined stress tolerance. Functional characterization of several TFs has revealed various members that confer both abiotic and biotic stress tolerance. Overexpression of the rice OsNAC6 conferred tolerance to salt and dehydration stress as well as resistance to blast disease (Nakashima et al., 2007). Similarly in wheat, overexpression of the R2R3MYB gene TaPIMP1 results in drought stress tolerance and resistance to Bipolaris sorokiniana through increased expression of abiotic stress (many of them ABA inducible) and defense-related genes (Zhang et al., 2012). Members of the AP2/ERF TF family have been shown to be positive regulators of both abiotic and biotic stress (Jung et al., 2007; Zhang et al., 2009). DREB TFs are also members of the AP2/ERF family and important contributors to abiotic stress tolerance (Liu et al., 2013a) that may have additional signaling functions for biotic stress tolerance. AtDREB2A was upregulated in plants overexpressing the CC-NB-LRR gene ADR1 which conferred pathogen resistance and drought tolerance (Chini et al., 2004). Overexpression of OsDREB1B in tobacco resulted in increased resistance to abiotic stress and also virus infection (Gutha and Reddy, 2008).

Overexpression of AtHSFA1b provided stress hormone independent, but $\mathrm{H}_{2} \mathrm{O}_{2}$ signaling dependent increased tolerance to drought and resistance to bacterial and oomycete pathogens (Bechtold etal., 2013). It appears that the HSF TF gene family has broad biological functions in ROS signaling and defense responses and SAR regulation (Miller et al., 2008; Pick et al., 2012), which can be further exploited for building broad stress tolerance into crops. Whole genome expression meta analyses can provide evidence of potential antagonistic regulation in different stress responses for a given $\mathrm{TF}$, by analyzing expression patterns under different stress conditions (Shaik and Ramakrishna, 2014). Detailed characterization of spatiotemporal expression and cis-element binding patterns is, however, required for the understanding of the underlying mode of regulation. This was recently elegantly demonstrated in the characterization of OsWRKY13 which exhibits tissue specific expression and condition specific binding to cis-elements of downstream genes and thereby inversely regulated resistance to drought and bacterial infection of rice (Xiao et al., 2013).

Functional conservation of TF functions across species can be exploited to take advantage of the wealth of experimental data generated in the model plant Arabidopsis thaliana. For example, the Arabidopsis AtBOS1, an R2R3MYB TF, as well as its homolog in tomato SIAIM1 appear to regulate tolerance to abiotic and biotic stress in the same way, as mutant plants exhibit reduced tolerance to salt stress as well as to Botrytis infection (Mengiste et al., 2003; Abuqamar et al., 2009). Further similar efforts should be undertaken to accelerate the translation of experimental observations obtained in model plants species to crops.

The results obtained by the functional characterization of TFs are encouraging as many of them appear to regulate crossresistance in a unidirectional manner, in contrast to the observations at the level of hormonal regulation that point to antagonistic relationships. Therefore, their manipulation offers many opportunities to bypass the antagonistic effects on abiotic and biotic stress tolerance observed in the more upstream regulatory nodes.

\section{Epigenetic modifications}

Epigenetic modifications such as DNA cytosine methylation and histone residues methylation and acetylation contribute to the transcriptional control of amongst others adaptive responses to environmental stimuli (Mirouze and Paszkowski, 2011). A significant portion of these modifications appears to be persistent across generations and significantly contributes to phenotypic variation (Johannes et al., 2009). While cytosine methylation generally has repressive effects on gene transcription, leading to gene silencing, histone modifications can lead to transcriptional activation 
through local chromatin de-condensation which facilitates the accessibility of TFs (Liu et al., 2010). Recently, epigenetic modifications and specifically chromatin-regulated gene activation have been proposed to govern priming responses (Conrath, 2011). Genome wide approaches studying DNA methylation under abiotic and biotic stress have demonstrated widespread methylation alterations (Bilichak et al., 2012; Dowen et al., 2012). It would be of particular interest to further examine the occurrence of differential alterations and their impact under combinatorial stress.

Functional studies of chromatin remodeling enzymes have revealed a functional involvement of these enzymes in the regulation of both abiotic and biotic stress responses. Histone deacetylase 19 (HDA19) mutants exhibit enhanced basal expression of many SA-responsive genes (Kim et al., 2008) but decreased expression of $\mathrm{ABA}$ and JA/ET-responsive genes, and the mutants are hypersensitive to salt stress (Chen etal., 2010b). The histone lysine methyltransferase ATX1 is likely to be involved in dehydration stress signaling, as atx1 mutants were sensitive to drought and ATX1 methyltransferase activity positively regulated the expression of the ABA biosynthesis enzyme NCED3 (Ding et al., 2011). Interestingly, down-regulation of the TF WRKY70 during dehydration stress coincided with decreased presence of ATX1 at the WRKY70 gene locus (Ndamukong et al., 2010).

Chromatin structure can also be altered by the active deposition of variants of the canonical histones. Deposition of one of the these variants, H2A.Z, is linked to transcriptional activation in response to environmental stimuli (Coleman-Derr and Zilberman, 2012), and disruption of this mechanism leads to misregulated responses to both pathogens and elevated temperature (March-Diaz et al., 2008; Kumar and Wigge, 2010).

It would be highly interesting to investigate how a previously imposed stress predisposes plants at the methylation and chromatin level for the encounter of a subsequent stress, (de)sensitizing subsequent responses. This type of acclimation/predisposition may even be a useful tool for preparing seeds and propagated material for stressful environments.

\section{R-gene resistance and systemic acquired resistance}

The plant immune system consists of successive layers counteracting suppression of defense responses by pathogens through secretion of effector proteins (Hemetsberger et al., 2012). Recognition of the effectors by corresponding R-genes belonging to NB-LRR protein family or the effect of effectors on intracellular host proteins (guarded proteins) results in effector-triggered immunity (ETI). This is usually but not always manifested by localized cell death, termed the hypersensitivity response (Coll et al., 2011). The complexity in the regulation of ETI is outlined by network analyses of individual and combined hormone mutants, which revealed compensatory interactions in contrast to synergistic interaction observed in PTI (PAMP-triggered immunity; Tsuda et al., 2009), and which may explain the robustness of ETI to genetic perturbations. This robustness may be ideal in building tolerance to combinatorial stress through pyramiding R-genes with genes conferring abiotic stress tolerance.

However, it is becoming clear that there are multiple aspects of regulation at the NB-LRR protein level that are indispensable for the deployment of R-gene resistance (Heidrich et al., 2012). These include spatial regulation of NB-LRR accumulation in cellular compartments (e.g., the nucleus). Reduction of nuclear NB-LRR accumulation was shown to be responsible for the heat stress attenuation of disease resistance conferred by the proteins SNC1 and RPS4 in Arabidopsis (Zhu et al., 2010; Mang et al., 2012). Interestingly, mutants with reduced sensitivity to heat-induced defense inhibition were found to be based on changes in among others ABA biosynthesis enzymes, indicating that abiotic stress factors may affect R-gene compartmentation through ABA biosynthesis and signaling, although no further evidence is available. In addition, chaperone-mediated transport and folding of NB-LRR protein is important for their activity (Hubert et al., 2009). The heat shock protein HSP90 is a component of this chaperone machinery. HSP90 is also required for the maintenance of folding of other proteins under stress conditions (Wang etal., 2004), and could potentially become limiting for proper R-gene signaling or stress protection under combined stress conditions. The recent discovery that NB-LRR protein accumulation is controlled by microRNAs (Zhai et al., 2011) adds a novel layer of regulation that would be interesting to investigate under different stress conditions (Kulcheski et al., 2011).

Initial pathogen perception and interception through PTI or ETI triggers systemic signals that prime plant defense responses to effectively counter subsequent infection attempts and limit spreading of the disease. This is referred to as SAR. Many compounds and genes have been identified that function in mobile signal generation and transport. Conversion of MeSA produced at the infection site to $S A$ at the systemic tissues appears to be a prerequisite for SAR manifestation (Park et al., 2007). Additional metabolites such as pipecolic acid, dehydroabietinal, azelaic acid, and glyceraldehyde 3-phosphate probably function in the amplification of the signal, with no clear conclusions yet on their precise placement in the SAR circuit pathway (Dempsey and Klessig, 2012). SAR has been shown to be affected by environmental conditions such as exposure to light (Griebel and Zeier, 2008) and abiotic stresses such as salinity, through ABA suppression of SA biosynthesis (Yasuda et al., 2008). The further investigation of the patterns of accumulation and transport of these metabolites under conditions of combined abiotic and biotic stress may reveal potential connections between their regulation and plant phenotypic responses to combined stress.

\section{APPROACHES FOR GENE IDENTIFICATION AND BREEDING FOR TOLERANCE TO STRESS COMBINATION}

In accordance with individual abiotic and biotic stressors, each abiotic stress/pathogen/host combination should be treated independently as, despite the potential universal applicability of some interactions that were characterized in Arabidopsis, many unique interactions may be crucial for the phenotypic response. As a result improving crops to these complex stress conditions first requires an extensive phenotypic characterization at different levels of cellular regulation, i.e., transcription, translation, posttranslation, and metabolites, as well as at different stages of plant development. As evidence from research on individual abiotic and biotic stress responses points to a strong dependency 
on developmental (Skirycz et al., 2010) as well as environmental factors (Luna etal., 2011), the environmental conditions and developmental stages of the plants should be appropriately defined before any interpretation of the phenotypic and molecular response can be done. Finally the different layers of defense can be differentially affected by abiotic stress imposition (Figure 2); therefore, the outcome of the interaction will vary with the defense mechanisms employed and on the pathogens involved.

Breeding for resistance to combinatorial stress is challenging. However, various novel approaches can aid in dissecting interactions between various types of stressors and identifying genetic components that can be breeding targets. The combination of different $\sim$ omics technologies has enabled the molecular dissection of plant phenotypes (Baerenfaller etal., 2012; Nagano etal., 2012). They provide information about the biological function of the whole gene set of an organism, and overlapping expression patterns might imply participation in common pathways (Quackenbush, 2003), enabling more efficient reverse genetic approaches. Utilization of ${ }^{\circ}$ omics in combination with forward genetic approaches like association mapping (Chan etal., 2011) may narrow down the candidate genes responsible for the observed phenotypes and provide targets for functional characterization, further manipulation and improvement of crops through breeding. As mentioned previously, currently there are limited studies on the $\sim$ omics characterization of combined abiotic and biotic stress tolerance, however, functional characterization of differentially regulated genes is starting to provide interesting candidates for combined stress tolerance and their mode of action (Atkinson et al., 2013).

Manipulations that induce resistance to abiotic and biotic stress such as application of priming chemicals, followed by comprehensive phenotypic characterization can be used for candidate gene identification and molecular processes underlying stress cross-tolerance. Utilization of pre-existing chemical libraries for compounds that can prime abiotic and/or biotic stress tolerance and identification of their mode of action through chemical genetics approaches can both provide biotechnological targets for crop stress improvement and an opportunity to directly use the identified chemical in agricultural practice if no unintended side effects are observed (Hicks and Raikhel, 2009; McCourt and Desveaux, 2010; Okamoto etal., 2013). Moreover as the effects of chemical priming are shown to, in part, be exerted through induction of phosphorylation and other post-translational modifications (Beckers et al., 2009), probing these modifications and genetically manipulating the underlying codons to constitutively mimic them (Riano-Pachon et al., 2010) can result in altered responses under combinatorial stress.

Breeding for resistance to exposure to combined abiotic and biotic stress by incorporation of genetic components regulating the response to both stresses faces various challenges. For example, TFs can have thousands of binding sites across the genome ( $\mathrm{Lu}$ et al., 2013), increasing the chance of unwanted pleiotropic effects and therefore more sophisticated deployment should be employed. Both expression regulation and binding specificity can be altered through promoter and binding domain engineering (Desai et al., 2009; Cox et al., 2013) which can be aided by comparative genomic

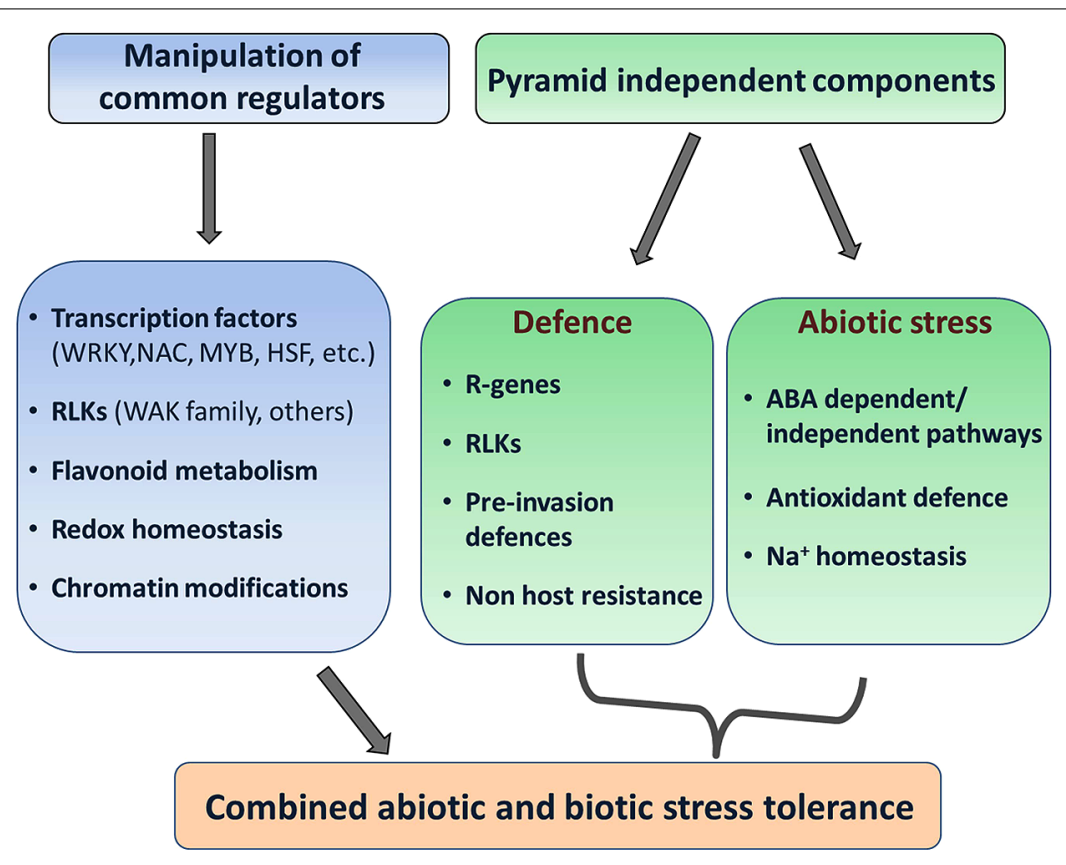

FIGURE 3 | Approaches for building combined abiotic and biotic stress tolerance in plants. Two strategies are proposed through either the manipulation of genetic components which potentially regulate resistance to both stresses in a preferentially unidirectional manner, or the pyramiding of genes that independently confer abiotic or biotic stress resistance and do not (negatively) interact. The selection of individual components might differ depending on the pathogen and the abiotic stress scenario. 
approaches (Korkuc et al., 2014) and applied through novel sitespecific mutagenesis techniques (Liu et al., 2013b). As selective and stimulus specific TF binding drives stress responses regulation (Xiao et al., 2013), implementation of the above methods will aid to fine-tune downstream targets toward the desired phenotypic response. A potential drawback of TF utilization is that resistance typically achieved by this approach is partial, and potentially prone to numerous antagonistic effects between stresses that cannot be predicted and can hinder efficient deployment for crop improvement to combined stresses.

Pyramiding genes that provide increased tolerance to either stress and do not (negatively) interact with each other offers an alternative route. Strong resistance mediated by R-genes, that appear to be robust to perturbations, can be pyramided with well-characterized genes conferring abiotic stress tolerance $(\mathrm{Hu}$ and Xiong, 2013; Kissoudis et al., unpublished data). R-gene robustness can be assessed by testing resistance responses under different abiotic stressors prior to pyramiding. The drawback of this approach is the quick breakdown of resistance due to evolving pathogens, and the fact that necrotrophic fungi resistance cannot be acquired with these genes. R-gene stacking aided by novel biotechnological approaches can reduce the risk of breakdown of R-gene-mediated resistance.

Pre-invasion defense mechanisms can be exploited, especially the one that is conferred by preformed or inducible physical barriers such as callose and antimicrobial compound deposition at the site of attempted penetration. As discussed earlier, callose deposition appears to be positively regulated by ABA signaling, therefore positive or no interaction should be expected under abiotic stress. Genes such as the OCP3 TF can be utilized, and for instance pyramiding abiotic stress tolerance with resistance conferred by $m l o$ loss of function which sensitizes callose deposition at the site of infection for resistance against powdery mildew (Buschges et al., 1997) may be a viable route (Kissoudis et al. unpublished data). However, pleiotropic effects reported in mlo mutants such as compromised resistance against necrotrophic pathogens (Kumar et al., 2001) and accelerated senescence (Piffanelli et al., 2002) can have adverse consequences under stress combination.

The mechanisms through which abiotic stress tolerance is conferred can have a differential effect on disease resistance. As mentioned earlier, drought tolerance through ABA upregulation at the whole-plant level is expected to have antagonistic effects with SA signaling and therefore compromises resistance to biotrophs. Localized ABA sensitization in stomata (Bauer et al., 2013) can overcome these drawbacks and offer an advantage for resistance against pathogen that infect through stomata. Manipulation of developmental traits such as root system architecture can be beneficial for drought tolerance (Uga et al., 2013) with potentially no adverse effects on disease resistance, as they employ cell type specific signaling. Deployment of genes that have a protective function on proteins and cellular components under abiotic stress, such as dehydrins, LEA proteins or RNA chaperones (Kang etal., 2013) that apparently are downstream components of abiotic stress adaptation and mostly function through their structural properties, can minimize interaction with biotic stress signaling. Moreover, under salt stress, increased tolerance through $\mathrm{Na}^{+}$compartmentalization in the vacuoles may offer an advantage in comparison with $\mathrm{Na}^{+}$exclusion, as $\mathrm{Na}^{+}$at high concentrations can have adverse effects on pathogen feeding and development.

Approaches that result in greater antioxidant capacity such as the accumulation of flavonoids appear to confer resistance to abiotic and oxidative stress (Nakabayashi et al., 2014) while overproduction of their derivatives, anthocyanins, increase resistance to the necrotrophic pathogen $B$. cinerea in tomato by minimizing ROS burst (Zhang et al., 2013). Therefore engineering for increased flavonoid accumulation can be promising in conferring resistance to multiple stressors, however, it is unknown how it can affect the deployment of hypersensitivity response due to disturbed ROS homeostasis and thus resistance against biotrophic pathogens.

Exploitation and deployment of different strategies (Figure 3) under different abiotic stress/pathogen combinations will demonstrate their feasibility and applicability, further leading toward the goal of breeding for crops that maintain their robustness and yield performance under diverse environmental conditions.

\section{ACKNOWLEDGMENT}

Christos Kissoudis is supported by "Alexander S. Onassis" Public Benefit Foundation scholarship.

\section{REFERENCES}

Abuqamar, S., Luo, H. L., Laluk, K., Mickelbart, M. V., and Mengiste, T. (2009). Crosstalk between biotic and abiotic stress responses in tomato is mediated by the AIM1 transcription factor. Plant J. 58, 347-360. doi: 10.1111/j.1365313X.2008.03783.x

Achard, P., Renou, J. P., Berthome, R., Harberd, N. P., and Genschik, P. (2008). Plant DELLAs restrain growth and promote survival of adversity by reducing the levels of reactive oxygen species. Curr. Biol. 18, 656-660. doi: 10.1016/j.cub.2008. 04.034

Achuo, E. A., Prinsen, E., and Hofte, M. (2006). Influence of drought, salt stress and abscisic acid on the resistance of tomato to Botrytis cinerea and Oidium neolycopersici. Plant Pathol. 55, 178-186. doi: 10.1111/j.1365-3059.2005. 01340.x

Adie, B. A. T., Perez-Perez, J., Perez-Perez, M. M., Godoy, M., Sanchez-Serrano, J. J., Schmelz, E. A., et al. (2007). ABA is an essential signal for plant resistance to pathogens affecting JA biosynthesis and the activation of defenses in Arabidopsis. Plant Cell 19, 1665-1681. doi: 10.1105/tpc.106.048041

Albrecht, C., Boutrot, F., Segonzac, C., Schwessinger, B., Gimenez-Ibanez, S., Chinchilla, D., et al. (2012). Brassinosteroids inhibit pathogen-associated molecular pattern-triggered immune signaling independent of the receptor kinase BAK1. Proc. Natl. Acad. Sci. U.S.A. 109, 303-308. doi: 10.1073/pnas.1109921108

Argueso, C. T., Ferreira, F. J., Epple, P., To, J. P. C., Hutchison, C. E., Schaller, G. E., etal. (2012). Two-component elements mediate interactions between cytokinin and salicylic acid in plant immunity. PLoS Genet. 8:e1002448. doi: 10.1371/journal.pgen.1002448

Asai, T., Tena, G., Plotnikova, J., Willmann, M. R., Chiu, W. L., Gomez-Gomez, L., et al. (2002). MAP kinase signalling cascade in Arabidopsis innate immunity. Nature 415, 977-983. doi: 10.1038/415977a

Asano, T., Hayashi, N., Kobayashi, M., Aoki, N., Miyao, A., Mitsuhara, I., et al. (2012). A rice calcium-dependent protein kinase OsCPK12 oppositely modulates saltstress tolerance and blast disease resistance. Plant J. 69, 26-36. doi: 10.1111/j.1365313X.2011.04766.x

Asselbergh, B., Curvers, K., Franca, S. C., Audenaert, K., Vuylsteke, M., Van Breusegem, F. et al. (2007). Resistance to Botrytis cinerea in sitiens, an abscisic acid-deficient tomato mutant, involves timely production of hydrogen peroxide and cell wall modifications in the epidermis. Plant Physiol. 144, 1863-1877. doi: 10.1104/pp.107.099226

Asselbergh, B., De Vleesschauwer, D., and Hofte, M. (2008). Global switches and fine-tuning-ABA modulates plant pathogen defense. Mol. Plant Microbe Interact. 21, 709-719. doi: 10.1094/MPMI-21-6-0709 
Astier, J., Rasul, S., Koen, E., Manzoor, H., Besson-Bard, A., Lamotte, O., et al. (2011). S-nitrosylation: an emerging post-translational protein modification in plants. Plant Sci. 181, 527-533. doi: 10.1016/j.plantsci.2011.02.011

Atkinson, N. J., Lilley, C. J., and Urwin, P. E. (2013). Identification of genes involved in the response of Arabidopsis to simultaneous biotic and abiotic stresses. Plant Physiol. 162, 2028-2041. doi: 10.1104/pp.113.222372

Atkinson, N. J., and Urwin, P. E. (2012). The interaction of plant biotic and abiotic stresses: from genes to the field. J. Exp. Bot. 63, 3523-3543. doi: 10.1093/jxb/ ers 100

Baerenfaller, K., Massonnet, C., Walsh, S., Baginsky, S., Buhlmann, P., Hennig, L., et al. (2012). Systems-based analysis of Arabidopsis leaf growth reveals adaptation to water deficit. Mol. Syst. Biol. 8, 606. doi: 10.1038/msb.2012.39

Bari, R., and Jones, J. D. (2009). Role of plant hormones in plant defence responses. Plant Mol. Biol. 69, 473-488. doi: 10.1007/s11103-008-9435-0

Bauer, H., Ache, P., Lautner, S., Fromm, J., Hartung, W., Al-Rasheid, K. A., et al. (2013). The stomatal response to reduced relative humidity requires guard cell-autonomous ABA synthesis. Curr. Biol. 23, 53-57. doi: 10.1016/j.cub.2012. 11.022

Baxter, A., Mittler, R., and Suzuki, N. (2014). ROS as key players in plant stress signalling. J. Exp. Bot. 65, 1229-1240. doi: 10.1093/jxb/ert375

Bechtold, U., Albihlal, W. S., Lawson, T., Fryer, M. J., Sparrow, P. A., Richard, F., etal. (2013). Arabidopsis HEAT SHOCK TRANSCRIPTION FACTORAlb overexpression enhances water productivity, resistance to drought, and infection. J. Exp. Bot. 64, 3467-3481. doi: 10.1093/jxb/ert185

Beckers, G. J., Jaskiewicz, M., Liu, Y., Underwood, W. R., He, S. Y., Zhang, S. et al. (2009). Mitogen-activated protein kinases 3 and 6 are required for full priming of stress responses in Arabidopsis thaliana. Plant Cell 21, 944-953. doi 10.1105/tpc.108.062158

Belkhadir, Y., Jaillais, Y., Epple, P., Balsemao-Pires, E., Dangl, J. L., and Chory, J. (2012). Brassinosteroids modulate the efficiency of plant immune responses to microbe-associated molecular patterns. Proc. Natl. Acad. Sci. U.S.A. 109, 297-302. doi: $10.1073 /$ pnas. 1112840108

Berendsen, R. L., Pieterse, C. M., and Bakker, P. A. (2012). The rhizosphere microbiome and plant health. Trends Plant Sci. 17, 478-486. doi: 10.1016/j.tplants.2012.04.001

Bessire, M., Chassot, C., Jacquat, A. C., Humphry, M., Borel, S., Petetot, J. M., et al. (2007). A permeable cuticle in Arabidopsis leads to a strong resistance to Botrytis cinerea. EMBO J. 26, 2158-2168. doi: 10.1038/sj.emboj.7601658

Bilgin, D. D., Zavala, J. A., Zhu, J., Clough, S. J., Ort, D. R., and Delucia, E. H. (2010). Biotic stress globally downregulates photosynthesis genes. Plant Cell Environ. 33, 1597-1613. doi: 10.1111/j.1365-3040.2010.02167.x

Bilichak, A., Ilnystkyy, Y., Hollunder, J., and Kovalchuk, I. (2012). The progeny of Arabidopsis thaliana plants exposed to salt exhibit changes in DNA methylation, histone modifications and gene expression. PLOS ONE 7:e30515. doi 10.1371/journal.pone.0030515

Blomberg, A., and Adler, L. (1993). "Tolerance of fungi to NaCl," in Stress Tolerance of Fungi, ed. D. H. Jenings (New York, NY: Marcel Dekker Inc.), 209-232.

Bolton, M. D. (2009). Current review: primary metabolism and plant defense-fuel for the fire. Mol. Plant Microbe Interact. 22, 487-497. doi: 10.1094/MPMI-22-50487

Boudsocq, M., Willmann, M. R., Mccormack, M., Lee, H., Shan, L., He, P., et al. (2010). Differential innate immune signalling via $\mathrm{Ca}(2+)$ sensor protein kinases. Nature 464, 418-422. doi: 10.1038/nature08794

Breeze, E., Harrison, E., Mchattie, S., Hughes, L., Hickman, R., Hill, C., et al (2011). High-resolution temporal profiling of transcripts during Arabidopsis lea senescence reveals a distinct chronology of processes and regulation. Plant Cell 23, 873-894. doi: 10.1105/tpc.111.083345

Buschges, R., Hollricher, K., Panstruga, R., Simons, G., Wolter, M., Frijters, A., et al. (1997). The barley Mlo gene: a novel control element of plant pathogen resistance. Cell 88, 695-705. doi: 10.1016/S0092-8674(00)81912-1

Chan, E. K., Rowe, H. C., Corwin, J. A., Joseph, B., and Kliebenstein, D. J. (2011). Combining genome-wide association mapping and transcriptional networks to identify novel genes controlling glucosinolates in Arabidopsis thaliana. PLoS Biol. 9:e1001125. doi: 10.1371/journal.pbio.1001125

Chaouch, S., and Noctor, G. (2010). Myo-inositol abolishes salicylic aciddependent cell death and pathogen defence responses triggered by peroxisomal hydrogen peroxide. New Phytol. 188, 711-718. doi: 10.1111/j.1469-8137.2010. 03453.x
Chen, L. Q., Hou, B. H., Lalonde, S., Takanaga, H., Hartung, M. L., Qu, X. Q., et al. (2010a). Sugar transporters for intercellular exchange and nutrition of pathogens. Nature 468, 527-532. doi: 10.1038/nature09606

Chen, L. T., Luo, M., Wang, Y. Y., and Wu, K. (2010b). Involvement of Arabidopsis histone deacetylase HDA6 in ABA and salt stress response. J. Exp. Bot. 61, 33453353. doi: 10.1093/jxb/erq154

Chen, R., Jiang, H. L., Li, L., Zhai, Q. Z., Qi, L. L., Zhou, W. K., et al. (2012). The Arabidopsis mediator subunit MED25 differentially regulates jasmonate and abscisic acid signaling through interacting with the MYC2 and ABI5 transcription factors. Plant Cell 24, 2898-2916. doi: 10.1105/tpc.112.098277

Chen, R. Q., Sun, S. L., Wang, C., Li, Y. S., Liang, Y., An, F. Y., et al. (2009). The Arabidopsis PARAQUAT RESISTANT2 gene encodes an $S$-nitrosoglutathione reductase that is a key regulator of cell death. Cell Res. 19, 1377-1387. doi: 10.1038/Cr.2009.117

Chinchilla, D., Shan, L., He, P., De Vries, S., and Kemmerling, B. (2009). One for all: the receptor-associated kinase BAK1. Trends Plant Sci. 14, 535-541. doi: 10.1016/j.tplants.2009.08.002

Chini, A., Grant, J. J., Seki, M., Shinozaki, K., and Loake, G. J. (2004). Drought tolerance established by enhanced expression of the CC-NBS-LRR gene, ADR1, requires salicylic acid, EDS1 and ABI1. Plant J. 38, 810-822. doi: 10.1111/j.1365313X.2004.02086.X

Choi, J., Huh, S. U., Kojima, M., Sakakibara, H., Paek, K. H., and Hwang, I. (2010). The cytokinin-activated transcription factor ARR2 promotes plant immunity via TGA3/NPR1-dependent salicylic acid signaling in Arabidopsis. Dev. Cell 19, 284-295. doi: 10.1016/j.devcel.2010.07.011

Clement, M., Leonhardt, N., Droillard, M. J., Reiter, I., Montillet, J. L., Genty, B., et al. (2011). The cytosolic/nuclear HSC70 and HSP90 molecular chaperones are important for stomatal closure and modulate abscisic acid-dependent physiological responses in Arabidopsis. Plant Physiol. 156, 1481-1492. doi: 10.1104/pp.111.174425

Clough, S. J., Fengler, K. A., Yu, I. C., Lippok, B., Smith, R. K., and Bent, A. F. (2000). The Arabidopsis dnd 1 "defense, no death" gene encodes a mutated cyclic nucleotide-gated ion channel. Proc. Natl. Acad. Sci. U.S.A. 97, 9323-9328. doi: $10.1073 /$ pnas. 150005697

Coleman-Derr, D., and Zilberman, D. (2012). Deposition of histone variant H2A.Z within gene bodies regulates responsive genes. PLoS Genet. 8:e1002988. doi: 10.1371/journal.pgen. 1002988

Coll, N. S., Epple, P., and Dangl, J. L. (2011). Programmed cell death in the plant immune system. Cell Death Differ. 18, 1247-1256. doi: 10.1038/cdd. 2011.37

Collins, N. C., Thordal-Christensen, H., Lipka, V., Bau, S., Kombrink, E., Qiu, J. L., et al. (2003). SNARE-protein-mediated disease resistance at the plant cell wall. Nature 425, 973-977. doi: 10.1038/Nature02076

Conrath, U. (2011). Molecular aspects of defence priming. Trends Plant Sci. 16, 524-531. doi: 10.1016/j.tplants.2011.06.004

Cox, R. S. III, Nishikata, K., Shimoyama, S., Yoshida, Y., Matsui, M., Makita, Y., et al. (2013). PromoterCAD: data-driven design of plant regulatory DNA. Nucleic Acids Res. 41, W569-W574. doi: 10.1093/nar/gkt518

Curvers, K., Seifi, H., Mouille, G., De Rycke, R., Asselbergh, B., Van Hecke, A., et al. (2010). Abscisic acid deficiency causes changes in cuticle permeability and pectin composition that influence tomato resistance to Botrytis cinerea. Plant Physiol. 154, 847-860. doi: 10.1104/pp.110.158972

Daudi, A., Cheng, Z. Y., O’Brien, J. A., Mammarella, N., Khan, S., Ausubel, F. M., et al. (2012). The apoplastic oxidative burst peroxidase in Arabidopsis is a major component of pattern-triggered immunity. Plant Cell 24, 275-287. doi: $10.1105 /$ tpc.111.093039

De Block, M., Verduyn, C., De Brouwer, D., and Cornelissen, M. (2005). Poly(ADPribose) polymerase in plants affects energy homeostasis, cell death and stress tolerance. Plant J. 41, 95-106. doi: 10.1111/j.1365-313X.2004.02277.x

Demidchik, V., Shabala, S. N., and Davies, J. M. (2007). Spatial variation in $\mathrm{H}_{2} \mathrm{O}_{2}$ response of Arabidopsis thaliana root epidermal $\mathrm{Ca}^{2+}$ flux and plasma membrane $\mathrm{Ca}^{2+}$ channels. Plant J. 49, 377-386. doi: 10.1111/j.1365-313X.2006.02971.x

Dempsey, D. A., and Klessig, D. F. (2012). SOS - too many signals for systemic acquired resistance? Trends Plant Sci. 17, 538-545. doi: 10.1016/j.tplants.2012.05.011

De Pinto, M. C., Locato, V., and De Gara, L. (2012). Redox regulation in plant programmed cell death. Plant Cell Environ. 35, 234-244. doi: 10.1111/j.13653040.2011.02387.x 
Desai, T. A., Rodionov, D. A., Gelfand, M. S., Alm, E. J., and Rao, C. V. (2009). Engineering transcription factors with novel DNA-binding specificity using comparative genomics. Nucleic Acids Res. 37, 2493-2503. doi: 10.1093/Nar/Gkp079

Desprez-Loustau, M. L., Marcais, B., Nageleisen, L. M., Piou, D., and Vannini, A. (2006). Interactive effects of drought and pathogens in forest trees. Ann. For. Sci 63, 597-612. doi: 10.1051/forest:2006040

De Torres Zabala, M., Bennett, M. H., Truman, W. H., and Grant, M. R. (2009). Antagonism between salicylic and abscisic acid reflects early hostpathogen conflict and moulds plant defence responses. Plant J. 59, 375-386. doi: 10.1111/j.1365-313X.2009.03875.x

De Vleesschauwer, D., Van Buyten, E., Satoh, K., Balidion, J., Mauleon, R., Choi, I. R., et al. (2012). Brassinosteroids antagonize gibberellin- and salicylate-mediated root immunity in rice. Plant Physiol. 158, 1833-1846. doi: 10.1104/pp.112. 193672

Ding, Y., Avramova, Z., and Fromm, M. (2011). The Arabidopsis trithoraxlike factor ATX1 functions in dehydration stress responses via ABA-dependent and ABA-independent pathways. Plant J. 66, 735-744. doi: 10.1111/j.1365313X.2011.04534.x

Divi, U. K., Rahman, T., and Krishna, P. (2010). Brassinosteroid-mediated stress tolerance in Arabidopsis shows interactions with abscisic acid, ethylene and salicylic acid pathways. BMC Plant Biol. 10:151. doi: 10.1186/1471-222910-151

Dodd, A. N., Kudla, J., and Sanders, D. (2010). The language of calcium signaling. Annu. Rev. Plant Biol. 61, 593-620. doi: 10.1146/annurev-arplant-070109104628

Dodd, I. C., and Perez-Alfocea, F. (2012). Microbial amelioration of crop salinity stress. J. Exp. Bot. 63, 3415-3428. doi: 10.1093/jxb/ers033

Doherty, C. J., Van Buskirk, H. A., Myers, S. J., and Thomashow, M. F. (2009). Roles for Arabidopsis CAMTA transcription factors in cold-regulated gene expression and freezing tolerance. Plant Cell 21, 972-984. doi: 10.1105/tpc.108 063958

Dowen, R. H., Pelizzola, M., Schmitz, R. J., Lister, R., Dowen, J. M., Nery, J. R., et al. (2012). Widespread dynamic DNA methylation in response to biotic stress. Proc. Natl. Acad. Sci. U.S.A. 109, E2183-E2191. doi: 10.1073/pnas.12093 29109

Du, L. Q., Ali, G. S., Simons, K. A., Hou, J. G., Yang, T. B., Reddy, A. S. N., et al. (2009) $\mathrm{Ca}^{2+} /$ calmodulin regulates salicylic-acid-mediated plant immunity. Nature 457, 1154-1116. doi: 10.1038/Nature07612

Dubiella, U., Seybold, H., Durian, G., Komander, E., Lassig, R., Witte, C. P., et al. (2013). Calcium-dependent protein kinase/NADPH oxidase activation circuit is required for rapid defense signal propagation. Proc. Natl. Acad. Sci. U.S.A. 110, 8744-8749. doi: 10.1073/pnas.1221294110

Ellinger, D., Naumann, M., Falter, C., Zwikowics, C., Jamrow, T., Manisseri, C., et al. (2013). Elevated early callose deposition results in complete penetration resistance to powdery mildew in Arabidopsis. Plant Physiol. 161, 1433-1444. doi: 10.1104/pp.112.211011

Essmann, J., Schmitz-Thom, I., Schon, H., Sonnewald, S., Weis, E., and Scharte J. (2008). RNA interference-mediated repression of cell wall invertase impairs defense in source leaves of tobacco. Plant Physiol. 147, 1288-1299. doi: $10.1104 /$ pp.108.121418

Felle, H. H., Herrmann, A., Hanstein, S., Huckelhoven, R., and Kogel, K. H. (2004). Apoplastic $\mathrm{pH}$ signaling in barley leaves attacked by the powdery mildew fungus Blumeria graminis f. sp. hordei. Mol. Plant Microbe Interact. 17, 118-123. doi: 10.1094/MPMI.2004.17.1.118

Finka, A., Cuendet, A. F., Maathuis, F. J., Saidi, Y., and Goloubinoff, P. (2012). Plasma membrane cyclic nucleotide gated calcium channels control land plan thermal sensing and acquired thermotolerance. Plant Cell 24, 3333-3348. doi: 10.1105/tpc.112.095844

Fones, H., Davis, C. A., Rico, A., Fang, F., Smith, J. A., and Preston, G. M. (2010). Metal hyperaccumulation armors plants against disease. PLoS Pathog. 6:e1001093. doi: 10.1371/journal.ppat.1001093

Foyer, C. H., and Noctor, G. (2005). Redox homeostasis and antioxidant signaling: a metabolic interface between stress perception and physiological responses. Plant Cell 17, 1866-1875. doi: 10.1105/tpc.105.033589

Garcia-Andrade, J., Ramirez, V., Flors, V., and Vera, P. (2011). Arabidopsis ocp3 mutant reveals a mechanism linking $\mathrm{ABA}$ and JA to pathogen-induced callose deposition. Plant J. 67, 783-794. doi: 10.1111/j.1365-313X.2011.04633.x
Garrett, K. A., Dendy, S. P., Frank, E. E., Rouse, M. N., and Travers, S. E. (2006). Climate change effects on plant disease: genomes to ecosystems. Annu. Rev. Phytopathol. 44, 489-509. doi: 10.1146/annurev.phyto.44.070505. 143420

Geilfus, C. M., and Muhling, K. H. (2011). Real-time imaging of leaf apoplastic $\mathrm{pH}$ dynamics in response to $\mathrm{NaCl}$ stress. Front. Plant Sci. 2:13. doi: 10.3389/fpls.2011.00013

Gifford, J. L., Jamshidiha, M., Mo, J., Ishida, H., and Vogel, H. J. (2013). Comparing the calcium binding abilities of two soybean calmodulins: towards understanding the divergent nature of plant calmodulins. Plant Cell 25, 4512-4524. doi: $10.1105 /$ tpc. 113.113183

Glazebrook, J. (2005). Contrasting mechanisms of defense against biotrophic and necrotrophic pathogens. Annu. Rev. Phytopathol. 43, 205-227. doi: 10.1146/annurev.phyto.43.040204.135923

Goel, A. K., Lundberg, D., Torres, M. A., Matthews, R., Akimoto-Tomiyama, C., Farmer, L., et al. (2008). The Pseudomonas syringae type III effector HopAM1 enhances virulence on water-stressed plants. Mol. Plant Microbe Interact. 21, 361-370. doi: 10.1094/MPMI-21-3-0361

Goellner, K., and Conrath, U. (2008). Priming: it's all the world to induced disease resistance. Eur. J. Plant Pathol. 121, 233-242. doi: 10.1007/s10658-0079251-4

Griebel, T., and Zeier, J. (2008). Light regulation and daytime dependency of inducible plant defenses in Arabidopsis: phytochrome signaling controls systemic acquired resistance rather than local defense. Plant Physiol. 147, 790-801. doi: 10.1104/pp.108.119503

Grimmer, M. K., John Foulkes, M., and Paveley, N. D. (2012). Foliar pathogenesis and plant water relations: a review. J. Exp. Bot. 63, 4321-4331. doi: $10.1093 /$ jxb/ers143

Gudesblat, G. E., Iusem, N. D., and Morris, P. C. (2007). Guard cell-specific inhibition of Arabidopsis MPK3 expression causes abnormal stomatal responses to abscisic acid and hydrogen peroxide. New Phytol. 173, 713-721. doi: 10.1111/j.1469-8137.2006.01953.x

Guo, K. M., Babourina, O., Christopher, D. A., Borsic, T., and Rengel, Z. (2010). The cyclic nucleotide-gated channel AtCNGC10 transports $\mathrm{Ca}^{2+}$ and $\mathrm{Mg}^{2+}$ in Arabidopsis. Physiol. Plant. 139, 303-312. doi: 10.1111/j.1399-3054.2010. 01366.x

Gutha, L. R., and Reddy, A. R. (2008). Rice DREB1B promoter shows distinct stress-specific responses, and the overexpression of cDNA in tobacco confers improved abiotic and biotic stress tolerance. Plant Mol. Biol. 68, 533-555. doi: 10.1007/s11103-008-9391-8

Hamaji, K., Nagira, M., Yoshida, K., Ohnishi, M., Oda, Y., Uemura, T., et al. (2009). Dynamic aspects of ion accumulation by vesicle traffic under salt stress in Arabidopsis. Plant Cell Physiol. 50, 2023-2033. doi: 10.1093/pcp/pcp143

Hamann, T., Bennett, M., Mansfield, J., and Somerville, C. (2009). Identification of cell-wall stress as a hexose-dependent and osmosensitive regulator of plant responses. Plant J. 57, 1015-1026. doi: 10.1111/j.1365-313X.2008.03744.x

Heidrich, K., Blanvillain-Baufume, S., and Parker, J. E. (2012). Molecular and spatial constraints on NB-LRR receptor signaling. Curr. Opin. Plant Biol. 15, 385-391. doi: 10.1016/j.pbi.2012.03.015

Hématy, K., Cherk, C., and Somerville, S. (2009). Host-pathogen warfare at the plant cell wall. Curr. Opin. Plant Biol. 12, 406-413. doi: 10.1016/j.pbi.2009. 06.007

Hemetsberger, C., Herrberger, C., Zechmann, B., Hillmer, M., and Doehlemann, G. (2012). The Ustilago maydis effector Pepl suppresses plant immunity by inhibition of host peroxidase activity. PLoS Pathog. 8:e1002684. doi: 10.1371/journal.ppat.1002684

Hicks, G. R., and Raikhel, N. V. (2009). Opportunities and challenges in plant chemical biology. Nat. Chem. Biol. 5, 268-272. doi: 10.1038/nchembio05 09-268

Horváth, E., Szalai, G., and Janda, T. (2007). Induction of abiotic stress tolerance by salicylic acid signaling. J. Plant Growth Regul. 26, 290-300. doi: 10.1007/s00344007-9017-4

Hou, X., Lee, L. Y., Xia, K., Yan, Y., and Yu, H. (2010). DELLAs modulate jasmonate signaling via competitive binding to JAZs. Dev. Cell 19, 884-894. doi: 10.1016/j.devcel.2010.10.024

Hu, H., and Xiong, L. (2013). Genetic engineering and breeding of drought-resistant crops. Annu. Rev. Plant Biol. 65, 715-774. doi: 10.1146/annurev-arplant-050213040000 
Huang, D., Wu, W., Abrams, S. R., and Cutler, A. J. (2008). The relationship of drought-related gene expression in Arabidopsis thaliana to hormonal and environmental factors. J. Exp. Bot. 59, 2991-3007. doi: 10.1093/jxb/ ern 155

Huang, X., Li, J., Bao, F., Zhang, X., and Yang, S. (2010). A gain-of-function mutation in the Arabidopsis disease resistance gene RPP4 confers sensitivity to low temperature. Plant Physiol. 154, 796-809. doi: 10.1104/pp.110. 157610

Hubert, D. A., He, Y., Mcnulty, B. C., Tornero, P., and Dangl, J. L. (2009). Specific Arabidopsis HSP90.2 alleles recapitulate RAR1 cochaperone function in plant NB-LRR disease resistance protein regulation. Proc. Natl. Acad. Sci. U.S.A. 106, 9556-9563. doi: 10.1073/pnas.0904877106

Hummel, I., Pantin, F., Sulpice, R., Piques, M., Rolland, G., Dauzat, M., et al. (2010). Arabidopsis plants acclimate to water deficit at low cost through changes of carbon usage: an integrated perspective using growth, metabolite, enzyme, and gene expression analysis. Plant Physiol. 154, 357-372. doi: 10.1104/pp.110. 157008

Jelenska, J., Van Hal, J. A., and Greenberg, J. T. (2010). Pseudomonas syringae hijacks plant stress chaperone machinery for virulence. Proc. Natl. Acad. Sci. U.S.A. 107, 13177-13182. doi: 10.1073/pnas.0910943107

Johannes, F., Porcher, E., Teixeira, F. K., Saliba-Colombani, V., Simon, M., Agier, N., etal. (2009). Assessing the impact of transgenerational epigenetic variation on complex traits. PLoS Genet. 5:e1000530. doi: 10.1371/journal.pgen.10 00530

Jung, J., Won, S. Y., Suh, S. C., Kim, H., Wing, R., Jeong, Y., et al. (2007). The barley ERF-type transcription factor HvRAF confers enhanced pathogen resistance and salt tolerance in Arabidopsis. Planta 225, 575-588. doi: 10.1007/s00425-0060373-2

Kachroo, P., Shanklin, J., Shah, J., Whittle, E. J., and Klessig, D. F. (2001). A fatty acid desaturase modulates the activation of defense signaling pathways in plants. Proc. Natl. Acad. Sci. U.S.A. 98, 9448-9453. doi: 10.1073/pnas.1512 58398

Kang, H., Park, S. J., and Kwak, K. J. (2013). Plant RNA chaperones in stress response. Trends Plant Sci. 18, 100-106. doi: 10.1016/j.tplants.2012.08.004

Kasuga, M., Miura, S., Shinozaki, K., and Yamaguchi-Shinozaki, K. (2004). A combination of the Arabidopsis DREB1A gene and stress-inducible rd29A promoter improved drought- and low-temperature stress tolerance in tobacco by gene transfer. Plant Cell Physiol. 45, 346-350. doi: 10.1093/pcp/pch037

Kim, J. I., Murphy, A. S., Baek, D., Lee, S. W., Yun, D. J., Bressan, R. A., et al. (2011a). YUCCA6 over-expression demonstrates auxin function in delaying leaf senescence in Arabidopsis thaliana. J. Exp. Bot. 62, 3981-3992. doi: 10.1093/jxb/err094

Kim, T. H., Hauser, F., Ha, T., Xue, S., Bohmer, M., Nishimura, N., et al. (2011b). Chemical genetics reveals negative regulation of abscisic acid signaling by a plant immune response pathway. Curr. Biol. 21, 990-997. doi: 10.1016/j.cub.2011.04.045

Kim, K. C., Lai, Z., Fan, B., and Chen, Z. (2008). Arabidopsis WRKY38 and WRKY62 transcription factors interact with histone deacetylase 19 in basal defense. Plant Cell 20, 2357-2371. doi: 10.1105/tpc.107.055566

Knepper, C., Savory, E. A., and Day, B. (2011). Arabidopsis NDR1 is an integrin-like protein with a role in fluid loss and plasma membrane-cell wall adhesion. Plant Physiol. 156, 286-300. doi: 10.1104/pp.110.169656

Kobayashi, M., Yoshioka, M., Asai, S., Nomura, H., Kuchimura, K., Mori, H., et al. (2012). StCDPK5 confers resistance to late blight pathogen but increases susceptibility to early blight pathogen in potato via reactive oxygen species burst. New Phytol. 196, 223-237. doi: 10.1111/j.1469-8137.2012.04226.x

Koh, S., Lee, S. C., Kim, M. K., Koh, J. H., Lee, S., An, G., et al. (2007). T-DNA tagged knockout mutation of rice OsGSK1, an orthologue of Arabidopsis BIN2, with enhanced tolerance to various abiotic stresses. Plant Mol. Biol. 65, 453-466. doi: 10.1007/s11103-007-9213-4

Kong, Q., Qu, N., Gao, M., Zhang, Z., Ding, X., Yang, F., et al. (2012). The MEKK1MKK1/MKK2-MPK4 kinase cascade negatively regulates immunity mediated by a mitogen-activated protein kinase kinase kinase in Arabidopsis. Plant Cell 24, 2225-2236. doi: 10.1105/tpc.112.097253

Koornneef, A., Leon-Reyes, A., Ritsema, T., Verhage, A., Den Otter, F. C., Van Loon, L. C., et al. (2008). Kinetics of salicylate-mediated suppression of jasmonate signaling reveal a role for redox modulation. Plant Physiol. 147, 1358-1368. doi: $10.1104 /$ pp.108.121392
Korkuc, P., Schippers, J. H., and Walther, D. (2014). Characterization and identification of cis-regulatory elements in Arabidopsis based on single-nucleotide polymorphism information. Plant Physiol. 164, 181-200. doi: 10.1104/pp.113. 229716

Korn, M., Gartner, T., Erban, A., Kopka, J., Selbig, J., and Hincha, D. K. (2010). Predicting Arabidopsis freezing tolerance and heterosis in freezing tolerance from metabolite composition. Mol. Plant 3, 224-235. doi: 10.1093/mp/ ssp 105

Kosma, D. K., Bourdenx, B., Bernard, A., Parsons, E. P., Lu, S., Joubes, J., et al. (2009). The impact of water deficiency on leaf cuticle lipids of Arabidopsis. Plant Physiol. 151, 1918-1929. doi: 10.1104/pp.109.141911

Koussevitzky, S., Suzuki, N., Huntington, S., Armijo, L., Sha, W., Cortes, D., et al. (2008). Ascorbate peroxidase 1 plays a key role in the response of Arabidopsis thaliana to stress combination. J. Biol. Chem. 283, 34197-34203. doi: 10.1074/jbc.M806337200

Kulcheski, F. R., De Oliveira, L. F., Molina, L. G., Almerao, M. P., Rodrigues, F. A., Marcolino, J., et al. (2011). Identification of novel soybean microRNAs involved in abiotic and biotic stresses. BMC Genomics 12:307. doi: 10.1186/1471-2164-12-307

Kumar, J., Huckelhoven, R., Beckhove, U., Nagarajan, S., and Kogel, K. H. (2001). A compromised Mlo pathway affects the response of barley to the necrotrophic fungus Bipolaris sorokiniana (Teleomorph: Cochliobolus sativus) and its toxins. Phytopathology 91, 127-133. doi: 10.1094/PHYTO.2001.91.2.127

Kumar, S. V., and Wigge, P. A. (2010). H2A.Z-containing nucleosomes mediate the thermosensory response in Arabidopsis. Cell 140, 136-147. doi: 10.1016/j.cell.2009.11.006

Lee, B. R., Kim, K. Y., Jung, W. J., Avice, J. C., Ourry, A., and Kim, T. H. (2007). Peroxidases and lignification in relation to the intensity of water-deficit stress in white clover (Trifolium repens L.). J. Exp. Bot. 58, 1271-1279. doi: 10.1093/jxb/erl280

Li, D., Liu, H., Zhang, H., Wang, X., and Song, F. (2008). OsBIRH1, a DEAD-box RNA helicase with functions in modulating defence responses against pathogen infection and oxidative stress. J. Exp. Bot. 59, 2133-2146. doi: 10.1093/jxb/ern072

Li, P. F., Chen, L., Zhou, Y. H., Xia, X. J., Shi, K., Chen, Z. X., et al. (2013). Brassinosteroids-induced systemic stress tolerance was associated with increased transcripts of several defence-related genes in the phloem in Cucumis sativus. PLoS ONE 8:e66582. doi: 10.1371/journal.pone.0066582

Lin, W., Lu, D., Gao, X., Jiang, S., Ma, X., Wang, Z., et al. (2013). Inverse modulation of plant immune and brassinosteroid signaling pathways by the receptor-like cytoplasmic kinase BIK1. Proc. Natl. Acad. Sci. U.S.A. 110, 12114-12119. doi: 10.1073/pnas. 1302154110

Lindner, H., Müller, L. M., Boisson-Dernier, A., and Grossniklaus, U. (2012). CrRLK1L receptor-like kinases: not just another brick in the wall. Curr. Opin. Plant Biol. 15, 659-669. doi: 10.1016/j.pbi.2012.07.003

Liu, C., Lu, F., Cui, X., and Cao, X. (2010). Histone methylation in higher plants. Annu. Rev. Plant Biol. 61, 395-420. doi: 10.1146/annurev.arplant.043008.091939 Liu, S., Wang, X., Wang, H., Xin, H., Yang, X., Yan, J., et al. (2013a). Genomewide analysis of $Z m D R E B$ genes and their association with natural variation in drought tolerance at seedling stage of Zea mays L. PLoS Genet. 9:e1003790. doi: 10.1371/journal.pgen. 1003790

Liu, W. S., Yuan, J. S., and Stewart, C. N. (2013b). Advanced genetic tools for plant biotechnology. Nat. Rev. Genet. 14, 781-793. doi: 10.1038/Nrg3583

Liu, Y., and Zhang, S. (2004). Phosphorylation of 1-aminocyclopropane-1carboxylic acid synthase by MPK6, a stress-responsive mitogen-activated protein kinase, induces ethylene biosynthesis in Arabidopsis. Plant Cell 16, 3386-3399. doi: 10.1105/tpc.104.026609

Locato, V., De Pinto, M. C., and De Gara, L. (2009). Different involvement of the mitochondrial, plastidial and cytosolic ascorbate-glutathione redox enzymes in heat shock responses. Physiol. Plant. 135, 296-306. doi: 10.1111/j.13993054.2008.01195.x

López, M. A., Bannenberg, G., and Castresana, C. (2008). Controlling hormone signaling is a plant and pathogen challenge for growth and survival. Curr. Opin. Plant Biol. 11, 420-427. doi: 10.1016/j.pbi.2008.05.002

Lu, Z., Yu, H., Xiong, G., Wang, J., Jiao, Y., Liu, G., et al. (2013). Genome-wide binding analysis of the transcription activator ideal plant architecturel reveals a complex network regulating rice plant architecture. Plant Cell 25, 3743-3759. doi: $10.1105 /$ tpc.113.113639

Luna, E., Pastor, V., Robert, J., Flors, V., Mauch-Mani, B., and Ton, J. (2011). Callose deposition: a multifaceted plant defense response. Mol. Plant Microbe Interact. 24, 183-193. doi: 10.1094/MPMI-07-10-0149 
Ma, S., and Bohnert, H. J. (2007). Integration of Arabidopsis thaliana stress-related transcript profiles, promoter structures, and cell-specific expression. Genome Biol. 8, R49. doi: 10.1186/gb-2007-8-4-r49

Ma, S., Gong, Q., and Bohnert, H. J. (2006). Dissecting salt stress pathways. J. Exp. Bot. 57, 1097-1107. doi: 10.1093/jxb/erj098

Mandal, M. K., Chandra-Shekara, A. C., Jeong, R. D., Yu, K., Zhu, S., Chanda, B., etal. (2012). Oleic acid-dependent modulation of NITRIC OXIDE ASSOCIATED1 protein levels regulates nitric oxide-mediated defense signaling in Arabidopsis. Plant Cell 24, 1654-1674. doi: 10.1105/tpc.112. 096768

Mang, H. G., Qian, W. Q., Zhu, Y., Qian, J., Kang, H. G., Klessig, D. F., et al. (2012). Abscisic acid deficiency antagonizes high-temperature inhibition of disease resistance through enhancing nuclear accumulation of resistance proteins SNC1 and RPS4 in Arabidopsis. Plant Cell 24, 1271-1284. doi: 10.1105/tpc.112. 096198

March-Diaz, R., Garcia-Dominguez, M., Lozano-Juste, J., Leon, J., Florencio, F. J., and Reyes, J. C. (2008). Histone H2A.Z and homologues of components of the SWR1 complex are required to control immunity in Arabidopsis. Plant J. 53, 475-487. doi: 10.1111/j.1365-313X.2007.03361.x

Marquez, L. M., Redman, R. S., Rodriguez, R. J., and Roossinck, M. J. (2007). A virus in a fungus in a plant: three-way symbiosis required for thermal tolerance. Science 315, 513-515. doi: 10.1126/science.1136237

Martí, M. C., Stancombe, M. A., and Webb, A. A. R. (2013). Cell- and stimulus typespecific intracellular free $\mathrm{Ca}^{2+}$ signals in Arabidopsis. Plant Physiol. 163, 625-634. doi: 10.1104/pp.113.222901

Mazzucotelli, E., Mastrangelo, A. M., Crosatti, C., Guerra, D., Stanca, A. M., and Cattivelli, L. (2008). Abiotic stress response in plants: when post-transcriptional and post-translational regulations control transcription. Plant Sci. 174, 420-431. doi: 10.1016/j.plantsci.2008.02.005

McCourt, P., and Desveaux, D. (2010). Plant chemical genetics. New Phytol. 185, 15-26. doi: 10.1111/j.1469-8137.2009.03045.x

McHale, L., Tan, X., Koehl, P., and Michelmore, R. W. (2006). Plant NBSLRR proteins: adaptable guards. Genome Biol. 7, 212. doi: 10.1186/gb-2006-74-212

Melotto, M., Underwood, W., Koczan, J., Nomura, K., and He, S. Y. (2006). Plant stomata function in innate immunity against bacterial invasion. Cell 126, 969980. doi: 10.1016/j.cell.2006.06.054

Mengiste, T., Chen, X., Salmeron, J., and Dietrich, R. (2003). The BOTRYTIS SUSCEPTIBLE1 gene encodes an R2R3MYB transcription factor protein that is required for biotic and abiotic stress responses in Arabidopsis. Plant Cell 15, 2551-2565. doi: 10.1105/Tpc.014167

Mhamdi, A., Hager, J., Chaouch, S., Queval, G., Han, Y., Taconnat, L., et al. (2010). Arabidopsis GLUTATHIONE REDUCTASE1 plays a crucial role in leaf responses to intracellular hydrogen peroxide and in ensuring appropriate gene expression through both salicylic acid and jasmonic acid signaling pathways. Plant Physiol. 153, 1144-1160. doi: 10.1104/pp.110.153767

Mhamdi, A., Han, Y., and Noctor, G. (2013). Glutathione-dependent phytohormone responses: teasing apart signaling and antioxidant functions. Plant Signal. Behav. 8, e24181. doi: 10.4161/psb.24181

Mi, S. K., Song, M. C., Eun, Y. K., Yang, J. I., Hwangbo, H., Young, C. K., et al. (2008). Galactinol is a signaling component of the induced systemic resistance caused by Pseudomonas chlororaphis O6 root colonization. Mol. Plant Microbe Interact. 21, 1643-1653. doi: 10.1094/MPMI-21-12-1643

Miller, G., Shulaev, V., and Mittler, R. (2008). Reactive oxygen signaling and abiotic stress. Physiol. Plant. 133, 481-489. doi: 10.1111/j.1399-3054.2008.01090.x

Mirouze, M., and Paszkowski, J. (2011). Epigenetic contribution to stress adaptation in plants. Curr. Opin. Plant Biol. 14, 267-274. doi: 10.1016/j.pbi.2011. 03.004

Mittler, R., Vanderauwera, S., Suzuki, N., Miller, G., Tognetti, V. B., Vandepoele, K., et al. (2011). ROS signaling: the new wave? Trends Plant Sci. 16, 300-309. doi: 10.1016/j.tplants.2011.03.007

Munne-Bosch, S., Queval, G., and Foyer, C. H. (2013). The impact of global change factors on redox signaling underpinning stress tolerance. Plant Physiol. 161, 5-19. doi: 10.1104/pp.112.205690

Munns, R., and Tester, M. (2008). Mechanisms of salinity tolerance. Annu. Rev. Plant Biol. 59, 651-681. doi: 10.1146/annurev.arplant.59.032607.092911

Nagano, A. J., Sato, Y., Mihara, M., Antonio, B. A., Motoyama, R., Itoh, H., et al. (2012). Deciphering and prediction of transcriptome dynamics under fluctuating field conditions. Cell 151, 1358-1369. doi: 10.1016/j.cell.2012. 10.048

Nakabayashi, R., Yonekura-Sakakibara, K., Urano, K., Suzuki, M., Yamada, Y., Nishizawa, T., et al. (2014). Enhancement of oxidative and drought tolerance in Arabidopsis by overaccumulation of antioxidant flavonoids. Plant J. 77, 367-379. doi: $10.1111 /$ tpj. 12388

Nakashima, K., Tran, L. S., Van Nguyen, D., Fujita, M., Maruyama, K., Todaka, D., et al. (2007). Functional analysis of a NAC-type transcription factor OsNAC6 involved in abiotic and biotic stress-responsive gene expression in rice. Plant J. 51, 617-630. doi: 10.1111/j.1365-313X.2007.03168.x

Nakashita, H., Yasuda, M., Nitta, T., Asami, T., Fujioka, S., Arai, Y., et al. (2003). Brassinosteroid functions in a broad range of disease resistance in tobacco and rice. Plant J. 33, 887-898. doi: 10.1046/j.1365-313X.2003.01675.x

Navarro, L., Bari, R., Achard, P., Lison, P., Nemri, A., Harberd, N. P., et al. (2008). DELLAs control plant immune responses by modulating the balance of jasmonic acid and salicylic acid signaling. Curr. Biol. 18, 650-655. doi: 10.1016/j.cub.2008.03.060

Ndamukong, I., Jones, D. R., Lapko, H., Divecha, N., and Avramova, Z. (2010). Phosphatidylinositol 5-phosphate links dehydration stress to the activity of ARABIDOPSIS TRITHORAX-LIKE factor ATX1. PLOS ONE 5:e13396. doi: 10.1371/journal.pone.0013396

Nemhauser, J. L., Hong, F. X., and Chory, J. (2006). Different plant hormones regulate similar processes through largely nonoverlapping transcriptional responses. Cell 126, 467-475. doi: 10.1016/j.cell.2006.05.050

Nishimura, N., Okamoto, M., Narusaka, M., Yasuda, M., Nakashita, H., Shinozaki, K., et al. (2009). ABA hypersensitive germination2-1 causes the activation of both abscisic acid and salicylic acid responses in Arabidopsis. Plant Cell Physiol. 50, 2112-2122. doi: 10.1093/Pcp/Pcp146

Obata, T., and Fernie, A. R. (2012). The use of metabolomics to dissect plant responses to abiotic stresses. Cell. Mol. Life Sci. 69, 3225-3243. doi: 10.1007/s00018-012-1091-5

Okamoto, M., Peterson, F. C., Defries, A., Park, S. Y., Endo, A., Nambara, E., et al. (2013). Activation of dimeric ABA receptors elicits guard cell closure, ABAregulated gene expression, and drought tolerance. Proc. Natl. Acad. Sci. U.S.A. 110, 12132-12137. doi: 10.1073/pnas.1305919110

Pajerowska-Mukhtar, K. M., Wang, W., Tada, Y., Oka, N., Tucker, C. L., Fonseca, J. P., et al. (2012). The HSF-like transcription factor TBF1 is a major molecular switch for plant growth-to-defense transition. Curr. Biol. 22, 103-112. doi: 10.1016/j.cub.2011.12.015

Park, S. W., Kaimoyo, E., Kumar, D., Mosher, S., and Klessig, D. F. (2007). Methyl salicylate is a critical mobile signal for plant systemic acquired resistance. Science 318, 113-116. doi: 10.1126/science. 1147113

Peleg, Z., and Blumwald, E. (2011). Hormone balance and abiotic stress tolerance in crop plants. Curr. Opin. Plant Biol. 14, 290-295. doi: 10.1016/j.pbi.2011. 02.001

Peters, G. P., Marland, G., Le Quéré, C., Boden, T., Canadell, J. G., and Raupach, M. R. (2011). Rapid growth of $\mathrm{CO}_{2}$ emission after the 2008-2009 global financial crisis. Nat. Clim. Change 2, 1-3. doi: 10.1038/nclimate1332

Pick, T., Jaskiewicz, M., Peterhansel, C., and Conrath, U. (2012). Heat shock factor $\mathrm{HsfB} 1$ primes gene transcription and systemic acquired resistance in Arabidopsis. Plant Physiol. 159, 52-55. doi: 10.1104/pp.111.191841

Pieterse, C. M., Leon-Reyes, A., Van Der Ent, S., and Van Wees, S. C. (2009). Networking by small-molecule hormones in plant immunity. Nat. Chem. Biol. 5 308-316. doi: 10.1038/nchembio.164

Piffanelli, P., Zhou, F. S., Casais, C., Orme, J., Jarosch, B., Schaffrath, U., et al. (2002). The barley MLO modulator of defense and cell death is responsive to biotic and abiotic stress stimuli. Plant Physiol. 129, 1076-1085. doi: 10.1104/Pp.010954

Pitzschke, A., Djamei, A., Bitton, F., and Hirt, H. (2009). A major role of the MEKK1-MKK1/2-MPK4 pathway in ROS signalling. Mol. Plant 2, 120-137. doi: $10.1093 / \mathrm{mp} / \mathrm{ssn} 079$

Popescu, S. C., Popescu, G. V., Bachan, S., Zhang, Z. M., Gerstein, M., Snyder, M., et al. (2009). MAPK target networks in Arabidopsis thaliana revealed using functional protein microarrays. Genes Dev. 23, 80-92. doi: 10.1101/Gad.17 40009

Popescu, S. C., Popescu, G. V., Bachan, S., Zhang, Z. M., Seay, M., Gerstein, M., et al. (2007). Differential binding of calmodulin-related proteins to their targets revealed through high-density Arabidopsis protein microarrays. Proc. Natl. Acad. Sci. U.S.A. 104, 4730-4735. doi: 10.1073/pnas.0611615104 
Poschenrieder, C., Tolrà, R., and Barceló, J. (2006). Can metals defend plants against biotic stress? Trends Plant Sci. 11, 288-295. doi: 10.1016/j.tplants.2006. 04.007

Potters, G., Horemans, N., and Jansen, M. A. (2010). The cellular redox state in plant stress biology - a charging concept. Plant Physiol. Biochem. 48, 292-300. doi: 10.1016/j.plaphy.2009.12.007

Prasch, C. M., and Sonnewald, U. (2013). Simultaneous application of heat, drought, and virus to Arabidopsis plants reveals significant shifts in signaling networks. Plant Physiol. 162, 1849-1866. doi: 10.1104/pp.113.221044

Quackenbush, J. (2003). Genomics. Microarrays - guilt by association. Science 302, 240-241. doi: 10.1126/science.1090887

Ramírez, V., Coego, A., López, A., Agorio, A., Flors, V., and Vera, P. (2009). Drought tolerance in Arabidopsis is controlled by the OCP3 disease resistance regulator. Plant J. 58, 578-591. doi: 10.1111/j.1365-313X.2009.03804.x

Rasmussen, S., Barah, P., Suarez-Rodriguez, M. C., Bressendorff, S., Friis, P., Costantino, P., etal. (2013). Transcriptome responses to combinations of stresses in Arabidopsis. Plant Physiol. 161, 1783-1794. doi: 10.1104/pp.112. 210773

Reinbothe, C., Springer, A., Samol, I., and Reinbothe, S. (2009). Plant oxylipins: role of jasmonic acid during programmed cell death, defence and leaf senescence. FEBS J. 276, 4666-4681. doi: 10.1111/j.1742-4658.2009.07193.x

Rentel, M. C., Lecourieux, D., Ouaked, F., Usher, S. L., Petersen, L., Okamoto, H., et al. (2004). OXI1 kinase is necessary for oxidative burst-mediated signalling in Arabidopsis. Nature 427, 858-861. doi: 10.1038/Nature02353

Reusche, M., Thole, K., Janz, D., Truskina, J., Rindfleisch, S., Drubert, C., et al (2012). Verticillium infection triggers VASCULAR-RELATED NAC DOMAIN7dependent de novo xylem formation and enhances drought tolerance in Arabidopsis. Plant Cell 24, 3823-3837. doi: 10.1105/tpc.112.103374

Riano-Pachon, D. M., Kleessen, S., Neigenfind, J., Durek, P., Weber, E., Engelsberger, W. R., et al. (2010). Proteome-wide survey of phosphorylation patterns affected by nuclear DNA polymorphisms in Arabidopsis thaliana. BMC Genomics 11:411. doi: 10.1186/1471-2164-11-411

Rizhsky, L., Liang, H., Shuman, J., Shulaev, V., Davletova, S., and Mittler, R. (2004). When defense pathways collide. The response of Arabidopsis to a combination of drought and heat stress $1[\mathrm{w}]$. Plant Physiol. 134, 1683-1696. doi 10.1104/pp.103.033431

Robert-Seilaniantz, A., Grant, M., and Jones, J. D. G. (2011). Hormone crosstalk in plant disease and defense: more than just JASMONATE-SALICYLATE antagonism. Annu. Rev. Phytopathol. 49, 317-343. doi: 10.1146/annurev-phyto-073009114447

Samajova, O., Komis, G., and Samaj, J. (2013). Emerging topics in the cell biology of mitogen-activated protein kinases. Trends Plant Sci. 18, 140-148. doi: 10.1016/j.tplants.2012.11.004

Sanchez-Vallet, A., Lopez, G., Ramos, B., Delgado-Cerezo, M., Riviere, M. P., Llorente, F., etal. (2012). Disruption of abscisic acid signaling constitutively activates Arabidopsis resistance to the necrotrophic fungus Plectosphaerella cucumerina. Plant Physiol. 160, 2109-2124. doi: 10.1104/pp.112.200154

Sanogo, S. (2004). Response of chile pepper to Phytophthora capsici in relation to soil salinity. Plant Dis. 88, 205-209. doi: 10.1094/Pdis.2004.88.2.205

Savchenko, T., Walley, J. W., Chehab, E. W., Xiao, Y., Kaspi, R., Pye, M. F., et al. (2010). Arachidonic acid: an evolutionarily conserved signaling molecule modulates plant stress signaling networks. Plant Cell 22, 3193-3205. doi: 10.1105/tpc.110. 073858

Schulz, P., Herde, M., and Romeis, T. (2013). Calcium-dependent protein kinases: hubs in plant stress signaling and development. Plant Physiol. 163, 523-530. doi: 10.1104/pp.113.222539

Segonzac, C., Feike, D., Gimenez-Ibanez, S., Hann, D. R., Zipfel, C., and Rathjen, J. P. (2011). Hierarchy and roles of pathogen-associated molecular patterninduced responses in Nicotiana benthamiana. Plant Physiol. 156, 687-699. doi: 10.1104/pp.110.171249

Senthil-Kumar, M., and Mysore, K. S. (2012). Ornithine-delta-aminotransferase and proline dehydrogenase genes play a role in non-host disease resistance by regulating pyrroline-5-carboxylate metabolism-induced hypersensitive response. Plant Cell Environ. 35, 1329-1343. doi: 10.1111/j.1365-3040.2012. 02492.x

Seo, Y. S., Chern, M., Bartley, L. E., Han, M., Jung, K. H., Lee, I., et al. (2011). Towards establishment of a rice stress response interactome. PLoS Genet. 7:e1002020. doi: 10.1371/journal.pgen.1002020
Shaik, R., and Ramakrishna, W. (2013). Genes and co-expression modules common to drought and bacterial stress responses in Arabidopsis and rice. PLoS ONE 8:e77261. doi: 10.1371/journal.pone.0077261

Shaik, R., and Ramakrishna, W. (2014). Machine learning approaches distinguish multiple stress conditions using stress-responsive genes and identify candidate genes for broad resistance in rice. Plant Physiol. 164, 481-495. doi: $10.1104 /$ pp.113.225862

Sharma, R., De Vleesschauwer, D., Sharma, M. K., and Ronald, P. C. (2013). Recent advances in dissecting stress-regulatory crosstalk in rice. Mol. Plant 6, 250-260. doi: $10.1093 / \mathrm{mp} / \mathrm{sss} 147$

Skirycz, A., De Bodt, S., Obata, T., De Clercq, I., Claeys, H., De Rycke, R., et al. (2010). Developmental stage specificity and the role of mitochondrial metabolism in the response of Arabidopsis leaves to prolonged mild osmotic stress. Plant Physiol. 152, 226-244. doi: 10.1104/pp.109.148965

Soliman, M. F., and Kostandi, S. F. (1998). Effect of saline environment on yield and smut disease severity of different corn genotypes (Zea mays L.). J. Phytopathol. 146, 185-189. doi: 10.1111/j.1439-0434.1998.tb04677.x

Tada, Y., Spoel, S. H., Pajerowska-Mukhtar, K., Mou, Z. L., Song, J. Q., Wang, C., etal. (2008). Plant immunity requires conformational charges of NPR1 via S-nitrosylation and thioredoxins. Science 321, 952-956. doi: 10.1126/science. 1156970

Takahashi, F., Mizoguchi, T., Yoshida, R., Ichimura, K., and Shinozaki, K. (2011). Calmodulin-dependent activation of MAP kinase for ROS homeostasis in Arabidopsis. Mol. Cell. 41, 649-660. doi: 10.1016/j.molcel.2011. 02.029

Tan, J. L., Wang, C. Y., Xiang, B., Han, R. H., and Guo, Z. F. (2013). Hydrogen peroxide and nitric oxide mediated cold- and dehydration-induced myo-inositol phosphate synthase that confers multiple resistances to abiotic stresses. Plant Cell Environ. 36, 288-299. doi: 10.1111/j.1365-3040.2012. 02573.x

Tang, D., Simonich, M. T., and Innes, R. W. (2007). Mutations in LACS2, a long-chain acyl-coenzyme A synthetase, enhance susceptibility to avirulent Pseudomonas syringae but confer resistance to Botrytis cinerea in Arabidopsis. Plant Physiol. 144, 1093-1103. doi: 10.1104/pp.106.094318

Tanou, G., Filippou, P., Belghazi, M., Job, D., Diamantidis, G., Fotopoulos, V., etal. (2012). Oxidative and nitrosative-based signaling and associated post-translational modifications orchestrate the acclimation of citrus plants to salinity stress. Plant J. 72, 585-599. doi: 10.1111/j.1365-313X.2012. 05100.x

Tanou, G., Molassiotis, A., and Diamantidis, G. (2009). Hydrogen peroxide- and nitric oxide-induced systemic antioxidant prime-like activity under $\mathrm{NaCl}$-stress and stress-free conditions in citrus plants. J. Plant Physiol. 166, 1904-1913. doi: 10.1016/j.jplph.2009.06.012

Tarantino, D., Vannini, C., Bracale, M., Campa, M., Soave, C., and Murgia, I. (2005). Antisense reduction of thylakoidal ascorbate peroxidase in Arabidopsis enhances paraquat-induced photooxidative stress and nitric oxide-induced cell death. Planta 221, 757-765. doi: 10.1007/s00425-0051485-9

Teige, M., Scheikl, E., Eulgem, T., Doczi, R., Ichimura, K., Shinozaki, K., etal. (2004). The MKK2 pathway mediates cold and salt stress signaling in Arabidopsis. Mol. Cell 15, 141-152. doi: 10.1016/j.molcel.2004. 06.023

Tena, G., Boudsocq, M., and Sheen, J. (2011). Protein kinase signaling networks in plant innate immunity. Curr. Opin. Plant Biol. 14, 519-529. doi: 10.1016/j.pbi.2011.05.006

Tian, M. Y., Von Dahl, C. C., Liu, P. P., Friso, G., Van Wijk, K. J., and Klessig, D. F. (2012). The combined use of photoaffinity labeling and surface plasmon resonance-based technology identifies multiple salicylic acid-binding proteins. Plant J. 72, 1027-1038. doi: 10.1111/Tpj.12016

Todesco, M., Balasubramanian, S., Hu, T. T., Traw, M. B., Horton, M., Epple, P., et al. (2010). Natural allelic variation underlying a major fitness trade-off in Arabidopsis thaliana. Nature 465, 632-636. doi: 10.1038/nature09083

Ton, J., Flors, V., and Mauch-Mani, B. (2009). The multifaceted role of ABA in disease resistance. Trends Plant Sci. 14, 310-317. doi: 10.1016/j.tplants.2009. 03.006

Ton, J., Jakab, G., Toquin, V., Flors, V., Iavicoli, A., Maeder, M. N., et al. (2005). Dissecting the $\beta$-aminobutyric acid-induced priming phenomenon in Arabidopsis. Plant Cell 17, 987-999. doi: 10.1105/tpc.104.029728 
Ton, J., and Mauch-Mani, B. (2004). $\beta$-amino-butyric acid-induced resistance against necrotrophic pathogens is based on ABA-dependent priming for callose. Plant J. 38, 119-130. doi: 10.1111/j.1365-313X.2004.02028.x

Triky-Dotan, S., Yermiyahu, U., Katan, J., and Gamliel, A. (2005). Development of crown and root rot disease of tomato under irrigation with saline water Phytopathology 95, 1438-1444. doi: 10.1094/PHYTO-95-1438

Tsuda, K., Sato, M., Stoddard, T., Glazebrook, J., and Katagiri, F. (2009). Network properties of robust immunity in plants. PLoS Genet. 5:e1000772. doi: 10.1371/journal.pgen.1000772

Uga, Y., Sugimoto, K., Ogawa, S., Rane, J., Ishitani, M., Hara, N., et al. (2013). Control of root system architecture by DEEPER ROOTING 1 increases rice yield under drought conditions. Nat. Genet. 45, 1097-1102. doi: 10.1038/ ng. 2725

Underwood, W., and Somerville, S. C. (2008). Focal accumulation of defences at sites of fungal pathogen attack. J. Exp. Bot. 59, 3501-3508. doi: 10.1093/Jxb/ Ern205

Upchurch, R. G. (2008). Fatty acid unsaturation, mobilization, and regulation in the response of plants to stress. Biotechnol. Lett. 30, 967-977. doi: 10.1007/s10529008-9639-Z

Urano, K., Maruyama, K., Ogata, Y., Morishita, Y., Takeda, M., Sakurai, N., et al. (2009). Characterization of the ABA-regulated global responses to dehydration in Arabidopsis by metabolomics. Plant J. 57, 1065-1078. doi: 10.1111/j.1365313X.2008.03748.x

Van Loon, L. C., Rep, M., and Pieterse, C. M. J. (2006). Significance of inducible defense-related proteins in infected plants. Annu. Rev. Phytopathol. 44, 135-162. doi: 10.1146/annurev.phyto.44.070505.143425

Vincent, D., Lapierre, C., Pollet, B., Cornic, G., Negroni, L., and Zivy, M. (2005). Water deficits affect caffeate $O$-methyltransferase, lignification, and related enzymes in maize leaves. A proteomic investigation. Plant Physiol. 137, 949-960. doi: 10.1104/pp.104.050815

Vlot, A. C., Dempsey, D. A., and Klessig, D. F. (2009). Salicylic acid, a multifaceted hormone to combat disease. Annu. Rev. Phytopathol. 47, 177-206. doi: 10.1146/annurev.phyto.050908.135202

Vogel, J. P., Raab, T. K., Somerville, C. R., and Somerville, S. C. (2004). Mutations in PMR5 result in powdery mildew resistance and altered cell wall composition. Plant J. 40, 968-978. doi: 10.1111/j.1365-313X.2004.02264.x

Walia, H., Wilson, C., Condamine, P., Liu, X., Ismail, A. M., and Close, T. J. (2007). Large-scale expression profiling and physiological characterization of jasmonic acid-mediated adaptation of barley to salinity stress. Plant Cell Environ. 30, 410-421. doi: 10.1111/j.1365-3040.2006.01628.x

Walley, J. W., Coughlan, S., Hudson, M. E., Covington, M. F., Kaspi, R., Banu, G., et al. (2007). Mechanical stress induces biotic and abiotic stress responses via a novel cis-element. PLoS Genet. 3:e172. doi: 10.1371/journal.pgen.00 30172

Wang, C., Cai, X., and Zheng, Z. (2005). High humidity represses Cf-4/Avr4- and Cf9/Avr9-dependent hypersensitive cell death and defense gene expression. Planta 222, 947-956. doi: 10.1007/s00425-005-0036-8

Wang, D., Pajerowska-Mukhtar, K., Culler, A. H., and Dong, X. N. (2007) Salicylic acid inhibits pathogen growth in plants through repression of the auxin signaling pathway. Curr. Biol. 17, 1784-1790. doi: 10.1016/j.cub.2007. 09.025

Wang, W., Vinocur, B., Shoseyov, O., and Altman, A. (2004). Role of plant heatshock proteins and molecular chaperones in the abiotic stress response. Trends Plant Sci. 9, 244-252. doi: 10.1016/j.tplants.2004.03.006

Wang, Y., Bao, Z., Zhu, Y., and Hua, J. (2009). Analysis of temperature modulation of plant defense against biotrophic microbes. Mol. Plant Microbe Interact. 22, 498-506. doi: 10.1094/MPMI-22-5-0498

Wang, Z. Y., Xiong, L. M., Li, W. B., Zhu, J. K., and Zhu, J. H. (2011). The plant cuticle is required for osmotic stress regulation of abscisic acid biosynthesis and osmotic stress tolerance in Arabidopsis. Plant Cell 23, 1971-1984. doi: $10.1105 /$ tpc. 110.081943

Widodo, Patterson, J. H., Newbigin, E., Tester, M., Bacic, A., and Roessner, U. (2009). Metabolic responses to salt stress of barley (Hordeum vulgare L.) cultivars, Sahara and Clipper, which differ in salinity tolerance. J. Exp. Bot. 60, 4089-4103. doi: 10.1093/Jxb/Erp243

Wiese, J., Kranz, T., and Schubert, S. (2004). Induction of pathogen resistance in barley by abiotic stress. Plant Biol. (Stuttg.) 6, 529-536. doi: 10.1055/s-2004821176
Wingler, A., and Roitsch, T. (2008). Metabolic regulation of leaf senescence: interactions of sugar signalling with biotic and abiotic stress responses. Plant Biol. (Stuttg.) 10(Suppl. 1), 50-62. doi: 10.1111/j.1438-8677.2008. 00086.x

Woldemariam, M. G., Onkokesung, N., Baldwin, I. T., and Galis, I. (2012). Jasmonoyl-L-isoleucine hydrolase 1 (JIH1) regulates jasmonoyl-L-isoleucine levels and attenuates plant defenses against herbivores. Plant J. 72, 758-767. doi: 10.1111/j.1365-313X.2012.05117.x

Wolters, H., and Jurgens, G. (2009). Survival of the flexible: hormonal growth control and adaptation in plant development. Nat. Rev. Genet. 10, 305-317. doi: $10.1038 /$ nrg2558

Wu, X. Y., Kuai, B. K., Jia, J. Z., and Jing, H. C. (2012a). Regulation of leaf senescence and crop genetic improvement. J. Integr. Plant Biol. 54, 936-952. doi: 10.1111/jipb.12005

Wu, Y., Zhang, D., Chu, J. Y., Boyle, P., Wang, Y., Brindle, I. D., et al. (2012b). The Arabidopsis NPR1 protein is a receptor for the plant defense hormone salicylic acid. Cell Rep. 1, 639-647. doi: 10.1016/j.celrep.2012.05.008

Xia, X. J., Wang, Y. J., Zhou, Y. H., Tao, Y., Mao, W. H., Shi, K., et al. (2009). Reactive oxygen species are involved in brassinosteroid-induced stress tolerance in cucumber. Plant Physiol. 150, 801-814. doi: 10.1104/pp.109. 138230

Xiao, F., Goodwin, S. M., Xiao, Y., Sun, Z., Baker, D., Tang, X., et al. (2004). Arabidopsis CYP86A2 represses Pseudomonas syringae type III genes and is required for cuticle development. EMBO J. 23, 2903-2913. doi: 10.1038/sj.emboj.7600290

Xiao, J., Cheng, H., Li, X., Xiao, J., Xu, C., and Wang, S. (2013). Rice WRKY13 regulates cross talk between abiotic and biotic stress signaling pathways by selective binding to different cis-elements. Plant Physiol. 163, 1868-1882. doi: 10.1104/pp.113.226019

Xing, Y., Jia, W., and Zhang, J. (2008). AtMKK1 mediates ABA-induced CAT1 expression and $\mathrm{H} 2 \mathrm{O} 2$ production via AtMPK6-coupled signaling in Arabidopsis. Plant J. 54, 440-451. doi: 10.1111/j.1365-313X.2008. 03433.x

Xiong, L., and Yang, Y. (2003). Disease resistance and abiotic stress tolerance in rice are inversely modulated by an abscisic acid-inducible mitogen-activated protein kinase. Plant Cell 15, 745-759. doi: 10.1105/tpc.008714

Xu, P., Chen, F., Mannas, J. P., Feldman, T., Sumner, L. W., and Roossinck, M. J. (2008). Virus infection improves drought tolerance. New Phytol. 180, 911-921. doi: $10.1111 / j .1469-8137.2008 .02627 . x$

Yasuda, M., Ishikawa, A., Jikumaru, Y., Seki, M., Umezawa, T., Asami, T., et al. (2008). Antagonistic interaction between systemic acquired resistance and the abscisic acid-mediated abiotic stress response in Arabidopsis. Plant Cell 20, 1678-1692. doi: 10.1105/tpc.107.054296

You, M. P., Colmer, T. D., and Barbetti, M. J. (2011). Salinity drives host reaction in Phaseolus vulgaris (common bean) to Macrophomina phaseolina. Funct. Plant Biol. 38, 984-992. doi: 10.1071/Fp11137

Yun, B. W., Feechan, A., Yin, M., Saidi, N. B., Le Bihan, T., Yu, M., et al. (2011). $S$-nitrosylation of NADPH oxidase regulates cell death in plant immunity. Nature 478, 264-268. doi: 10.1038/nature 10427

Zeier, J. (2013). New insights into the regulation of plant immunity by amino acid metabolic pathways. Plant Cell Environ. 36, 2085-2103. doi: 10.1111/Pce. 12122

Zhai, J. X., Jeong, D. H., De Paoli, E., Park, S., Rosen, B. D., Li, Y. P., et al. (2011). MicroRNAs as master regulators of the plant NB-LRR defense gene family via the production of phased, trans-acting siRNAs. Genes Dev. 25, 2540-2553. doi: 10.1101/gad.177527.111

Zhang, G., Chen, M., Li, L., Xu, Z., Chen, X., Guo, J., et al. (2009). Overexpression of the soybean GmERF3 gene, an AP2/ERF type transcription factor for increased tolerances to salt, drought, and diseases in transgenic tobacco. J. Exp. Bot. 60, 3781-3796. doi: 10.1093/jxb/erp214

Zhang, J., Shao, F., Li, Y., Cui, H., Chen, L., Li, H., et al. (2007). A Pseudomonas syringae effector inactivates MAPKs to suppress PAMP-induced immunity in plants. Cell Host Microbe 1, 175-185. doi: 10.1016/j.chom.2007. 03.006

Zhang, M., Barg, R., Yin, M., Gueta-Dahan, Y., Leikin-Frenkel, A., Salts, Y., et al. (2005). Modulated fatty acid desaturation via overexpression of two distinct $\omega-3$ desaturases differentially alters tolerance to various abiotic stresses in transgenic tobacco cells and plants. Plant J. 44, 361-371. doi: 10.1111/j.1365-313X.2005.02536.x 
Zhang, Y., Butelli, E., De Stefano, R., Schoonbeek, H. J., Magusin, A., Pagliarani, C., et al. (2013). Anthocyanins double the shelf life of tomatoes by delaying overripening and reducing susceptibility to gray mold. Curr. Biol. 23, 1094-1100. doi: 10.1016/j.cub.2013.04.072

Zhang, Z. Y., Liu, X., Wang, X. D., Zhou, M. P., Zhou, X. Y., Ye, X. G., et al. (2012). An R2R3 MYB transcription factor in wheat, TaPIMP1, mediates host resistance to Bipolaris sorokiniana and drought stresses through regulation of defense- and stress-related genes. New Phytol. 196, 1155-1170. doi: 10.1111/j.1469-8137.2012.04353.x

Zhao, M. S., and Running, S. W. (2010). Drought-induced reduction in global terrestrial net primary production from 2000 through 2009. Science 329, 940-943. doi: 10.1126/science.1192666

Zhu, S. Y., Yu, X. C., Wang, X. J., Zhao, R., Li, Y., Fan, R. C., et al. (2007). Two calcium-dependent protein kinases, CPK4 and CPK11, regulate abscisic acid signal transduction in Arabidopsis. Plant Cell 19, 3019-3036. doi: 10.1105/tpc.107.050666

Zhu, Y., Qian, W. Q., and Hua, J. (2010). Temperature modulates plant defense responses through NB-LRR proteins. PLoS Pathog. 6:e1000844. doi: 10.1371/journal.ppat.1000844

Zhu, Z., An, F., Feng, Y., Li, P., Xue, L., A, M., et al. (2011). Derepression of ethylenestabilized transcription factors (EIN3/EIL1) mediates jasmonate and ethylene signaling synergy in Arabidopsis. Proc. Natl. Acad. Sci. U.S.A. 108, 12539-12544. doi: 10.1073/pnas.1103959108
Zou, C., Sun, K., Mackaluso, J. D., Seddon, A. E., Jin, R., Thomashow, M. F., et al. (2011). Cis-regulatory code of stress-responsive transcription in Arabidopsis thaliana. Proc. Natl. Acad. Sci. U.S.A. 108, 14992-14997. doi: 10.1073/pnas.1103202108

Conflict of Interest Statement: The authors declare that the research was conducted in the absence of any commercial or financial relationships that could be construed as a potential conflict of interest.

Received: 18 March 2014; accepted: 28 April 2014; published online: 19 May 2014. Citation: Kissoudis C, van de Wiel C, Visser RGF and van der Linden G (2014) Enhancing crop resilience to combined abiotic and biotic stress through the dissection of physiological and molecular crosstalk. Front. Plant Sci. 5:207. doi: 10.3389/fpls.2014.00207

This article was submitted to Crop Science and Horticulture, a section of the journal Frontiers in Plant Science.

Copyright (C) 2014 Kissoudis, van de Wiel, Visser and van der Linden. This is an open-access article distributed under the terms of the Creative Commons Attribution License (CC BY). The use, distribution or reproduction in other forums is permitted, provided the original author(s) or licensor are credited and that the original publication in this journal is cited, in accordance with accepted academic practice. No use, distribution or reproduction is permitted which does not comply with these terms. 